\title{
Multivalent electrolyte induced surface ordering and solution self- assembly in anionic surfactant mixtures: sodium dodecyl sulfate and sodium diethylene glycol monododecyl sulfate.
}

Peixun $\mathrm{Li}^{1}$, Zi Wang ${ }^{1}$, Kun $\mathrm{Ma}^{1}$, Yao Chen ${ }^{1}$, Ziefeng Yan $^{3 *}$, Jeff Penfold ${ }^{1,2 *}$, Robert K Thomas $^{2}$, Mario Campana ${ }^{1}$, John R P Webster ${ }^{1}$, Adam Washington ${ }^{1}$

1. ISIS Facility, Rutherford Appleton Laboratory, STFC, Chilton, Didcot, OXON, OX11 OQX, UK

2. Physical and Theoretical Chemistry Laboratory, Oxford University, South Parks Road, Oxford, OX1 3QZ, UK

3. School of Science, State Key Laboratory of Heavy Oil Processing, China University of Petroleum, Qingdao 266580, China

Joint Corresponding authors: Jeffrey Penfold, jeff.penfold@stfc.ac.uk; Yan Zifeng, zfyancat@upc.edu.cn

Keywords: anionic surfactant mixtures, sodium dodecyl sulfate, sodium diethylene glycol monododecyl sulfate, surface adsorption, surface layering, air-water interface, self-assembly 


\begin{abstract}
The formation of surface multilayer structures, with the addition of multivalent electrolytes, has been observed in a range of different anionic surfactants; and notably the sodium oxyethylene glycol alkyl sulfate, SAES, and alkyl ester sulfonate, AES, surfactants. The addition of increasing amounts of $\mathrm{AlCl}_{3}$ results in increasing surface layering, with a transition from monolayer to bilayer to ultimately more extended multilayer structures at the interface.
\end{abstract}

The headgroup structures of these SAES and AES surfactants and their hydrophilic / hydrophobic balance give a degree of tolerance to the precipitation induced by multivalent counterions. This was considered to be important factor associated with the multivalent counterion induced surface layering. In this paper the impact of sodium dodecyl sulfate, SDS, an anionic surfactant more susceptible to precipitation in the presence of multivalent counterions, on the surface multilayer formation and solution self-assembly of sodium diethylene glycol monododecyl sulfate, SLES, is explored using surface tension, neutron reflectivity and small angle neutron scattering.

The results show that SDS exhibits a similar progressive evolution in surface structures with increasing $\mathrm{AlCl}_{3}$ concentrations, as observed in SLES and related SAES surfactants, and in MES, sodium methyl ester dodecyl sulfonate surfactant. However in the SLES / SDS mixtures the structural evolution is different, and more complex pattern with increasing $\mathrm{AlCl}_{3}$ concentration is observed. The initial transition from monolayer to bilayer / trilayer structures exists, but the surface at higher $\mathrm{AlCl}_{3}$ concentration reverts to monolayer adsorption before extended multilayer structures are formed. Complementary small angle neutron scattering measurements indicate a more complex evolution in the micelle structure which broadly correlates with the surface behaviour.

The results illustrate how subtle changes in headgroup structure and packing affect relative counterion binding and hence the surface and solution structures. The results reinforce and extend the observations of related structures on different SAES and AES surfactants, and highlight the opportunity for manipulating surface adsorption behaviour with surfactant mixtures. 


\section{INTRODUCTION}

Anionic surfactants are the major components in a range of surfactant based formulations, which, for example, include most home and personal care products $(1,2)$. The impact of the addition of electrolyte to such aqueous solutions is well established $(3,4)$. For monovalent electrolytes such as $\mathrm{NaCl}$ it results in the onset of micellisation, critical micelle concentration, cmc, at lower surfactant concentrations (4), micellar growth $(3,5,6)$, and enhanced adsorption at interfaces (7). At higher $\mathrm{NaCl}$ concentrations (8), and especially for multivalent electrolytes such as $\mathrm{CaCl}_{2}$ and $\mathrm{AlCl}_{3}$ at more modest concentrations, it also leads to the onset of precipitation (9-14). This is the origin of phenomena such as water hardness in detergency (8, $9)$, and is used in environmental applications to remove heavy metal contaminants $(15,16)$. However, it is mostly seen as a phenomena which should be avoided in order to optimised the performance of particular formulations. A variety of different strategies have been adopted to minimise precipitation effects, such as mixing the anionic surfactant with a nonionic surfactant (17) and modifying the surfactant structure $(1,2)$. One of the simplest and most common anionic surfactants, the alkyl sulfates and especially sodium dodecyl sulfate, SDS, is one of the surfactants most sensitive to precipitation in the presence of multivalent counterions (8). Different structures such as sodium dodecyl benzene sulfonate, LAS, sodium oxyethylene glycol monododecyl ether sulfate, SLES, and sodium tetradecanoic 2-sulfo 1-methyl ester, MES, provide greater and differing degrees of tolerance to the detrimental effects of multivalent counterions $(1,2)$.

More recently it has been demonstrated using neutron reflectivity, NR, that the addition of multivalent counterions can induce surface multilayer formation at the air-water interface (18, 19). This can be used advantageously to enhance phenomena such as detergency or provide a near surface reservoir for the efficient surface delivery of other active components in a range of formulations. This surface layering has been demonstrated to occur for LAS with the addition of $\mathrm{Ca}^{2+}$ (20-22), and for SLES and MES with the addition of $\mathrm{Al}^{3+}$ (23-29). With increasing electrolyte concentration there is a transition from monolayer adsorption, $S_{1}$, to surface structures with increasingly extended multilayer structures. Transitions from monolayer, $S_{1}$, to a monolayer with a surfactant bilayer beneath, $S_{2}$, to 2 and 3 bilayers, $S_{3}, S_{4}$, and to extended multilayer structures, $\mathrm{S}_{\mathrm{n}}$, have all been observed and characterised.

Micellar growth in the presence of electrolyte is well established and characterised $(3,5,6)$, and continues to attract much attention for a wide range of systems of emerging importance 
(30-35), both experimentally and theoretically. Alargova et al $(36,37)$ highlighted the particular role of multivalent counterions, and especially the trivalent $\mathrm{Al}^{3+}$ counterions, in micellar growth. Of particular relevance here is the micellar growth in the presence of di and tri-valent counterions, the onset of the formation of lamellar precipitates, and the relationship between the bulk and corresponding surface behaviours (21-23, 30, 38-40).

Thomas et al (19) have recently reviewed the extent of such surface layering, its relationship with the associated bulk phase behaviour, and the origins of the attractive interaction required to promote the formation of such surface structures. It has been shown that the relative binding of $\mathrm{Na}^{+}$and $\mathrm{Al}^{3+}\left(\mathrm{Ca}^{2+}\right)$ is of particular significance (30). It was initiallly assumed that the surface layering will occur particularly when the surfactant headgroup structure allows a degree of tolerance to precipitation due to changes in the balance of the relative counterion binding. However of particular relevance to this paper is the observation from Thomas et al (19) that the surface layering often occurs outside the regime where precipitation occurs, and this provides a wider range of interesting opportunities.

The focus of this study was hence to explore the extent to which surface layering would occur for SDS, which is relatively sensitive to precipitation in the presence of multivalent ions, and to what extent blending with an anionic surfactant more tolerant to precipitation, such as SLES, will modify that surface behaviour. NR measurements were made at the air-water interface for SLES / SDS mixtures to characterise the surface mixing in the absence of electrolyte, and then in the presence of increasing $\mathrm{AlCl}_{3}$ concentrations for SDS to SLES rich solution compositions, in order to determine the pattern of the evolution in the surface structure. Small angle neutron scattering, SANS, measurements were made in the absence of electrolyte and in the presence of $\mathrm{AlCl}_{3}$ at solution concentrations relatively close to the $\mathrm{cmc}$; in order to complement and augment the NR data. Access to both the surface and solution properties in broadly similar circumstances should provide the opportunity to more fully understand the way the surface properties evolve with solution composition and $\mathrm{AlCl}_{3}$ concentration.

\section{EXPERIMENTAL DETAILS}

Surface tension, ST, measurements were made using a Kruss K11 maximum pull tensiometer to determine the variation in the cmc with surfactant composition for the SLES / SDS mixture in the absence of electrolyte, using established procedures which are describe in more detail in the Supporting Information. 
The neutron reflectivity, NR, measurements were made at the air-water interface, in the absence and in the presence of $\mathrm{AlCl}_{3}$, on the CRISP and SURF reflectometers (41, 42), using established procedures, which are described in more detail in the Supporting Information, to measure the reflectivity, $\mathrm{R}(\mathrm{Q})$, versus wave vector transfer, $\mathrm{Q}$ (where $\mathrm{Q}$ is defined as $\mathrm{Q}=4 \pi / \lambda \sin \theta, \lambda$ is the neutron wavelength, and $\theta$ is the glancing angle of incidence). The reflectivity is established on an absolute scale over a $\mathrm{Q}$ range $\sim 0.04$ to $0.4 \AA^{-1}$ using the white beam time of flight method (43). The measurements were all made in null reflecting water, nrw, (8 mole $\% \mathrm{D}_{2} \mathrm{O} / 92$ mole $\% \mathrm{H}_{2} \mathrm{O}$, with a scattering length density or neutron refractive index equal to air) subphase, using deuterium labelled surfactants.

The NR measurements were made on solutions contained in Teflon troughs and in a sealed environment at $25^{\circ} \mathrm{C}$. Each NR measurement was $\sim 20$ to 30 minutes (depending upon the individual instrument) and the samples were sequentially measured in a 4 or 5 position sample changer. In $\mathrm{AlCl}_{3}$ repeated measurements were made until the reflectivity data no longer changed with time, and this typically corresponded to a total lapse time $\sim 2-5$ hours and $\sim 2-3$ repeated measurements.

The sodium diethylene glycol monododecyl ether sulfate, SLES, and sodium dodecyl sulfate, SDS, surfactants, with the basic formula $\mathrm{CH}_{3}\left(\mathrm{CH}_{2}\right)_{11}\left(\mathrm{OCH}_{2} \mathrm{CH}_{2}\right)_{2} \mathrm{SO}_{4} \mathrm{Na}$ and $\mathrm{CH}_{3}\left(\mathrm{CH}_{2}\right)_{11} \mathrm{SO}_{4} \mathrm{Na}$, (hydrogeneous and alkyl chain deuterium labelled versions, abbrevaiated h, d-SLES and h, d-SDS) were synthesised and purified as described in detail elsewhere (44, 45). No adjustments to the solution $\mathrm{pH}$ were made on the addition of $\mathrm{AlCl}_{3}$, and the $\mathrm{pH}$ decreased from $\sim 7$ to $\sim 4.5$ depending upon the $\mathrm{AlCl}_{3}$ concentration. Further experimental details associated with the sample preparation are described in more detail in the Supporting Information.

The SANS measurements were made on the LARMOR instrument (46), operating in its SANS mode using the white beam time of flight method. Further experimental details and details of the data analysis (47) are provided in the Supporting Information. The measurements were made in $1 \mathrm{~mm}$ path length quartz spectrophotometer cells at $25^{\circ} \mathrm{C}$, and each individual measurement was $\sim 30$ mins. The measurements were made primarily for the isotopic combinations of h-SLES / h-SDS and h-SLES / d-SDS in $\mathrm{D}_{2} \mathrm{O}$ at different surfactant compositions and concentrations and for a range of $\mathrm{AlCl}_{3}$ concentrations. At the relatively low surfactant concentrations studied the subtraction of the background scattering from the solvent and cell and the scattering close to the beamstop limit the usable Q range to $\sim 0.01$ to $0.3 \AA^{-1}$. 


\section{RESULTS and DISCUSSION}

\section{(a) Surface Adsorption of SLES / SDS mixtures in the absence of electrolyte}

The mixing properties of the SLES / SDS surfactant mixtures were determined in the absence of electrolyte using ST and NR. The solution mixing properties were evaluated from the variation of the cmc with solution composition, as shown in figure 1a, and for the cmc values tabulated in table $\mathrm{S} 1$ in the Supporting Information, and for the surface tension data shown in figure S1 in the Supporting Information.

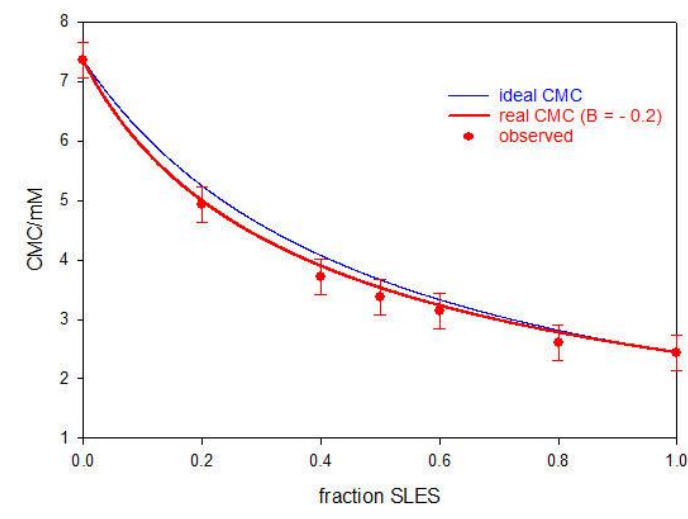

(a)

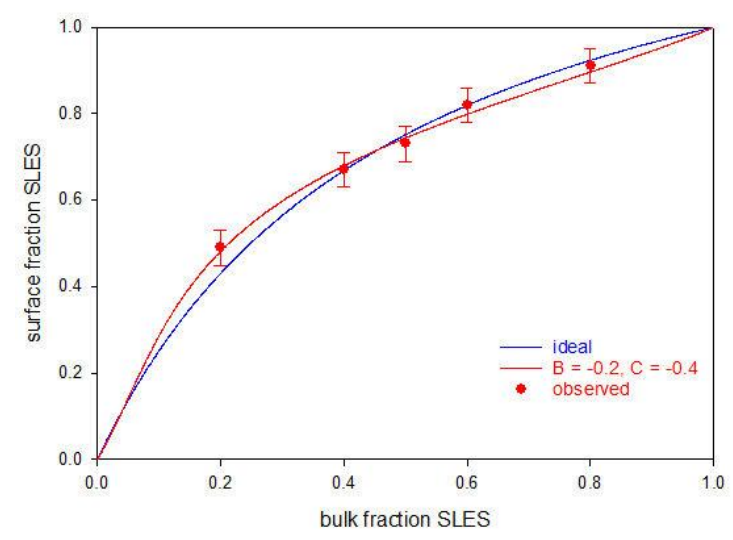

(b)

Figure 1. (a) Variation in mixed cmc with solution composition for SLES / SDS. The blue line is for ideal mixing, and the red line for non-ideal mixing with $B=-0.2$, as described in the main text, (b) Variation in surface composition versus solution composition, at a surfactant concentration of $2 \mathrm{mM}$. The blue line is for ideal surface mixing and the red line is non-ideal mixing with $B=-0.2$ and $C=-0.4$, as described in the main text. See legend for further details.

Recent developments in the application of the Pseudo Phase Approximation, PPA, to micelle and surface mixing are used here to quantitatively evaluate the mixing properties $(45,49)$. In the Pseudo Phase Approximation the chemical potential of the pseudo phases, micelle, monomer and surface, are equal (51-53), and equating, for example, the micelle and monomer chemical potential gives rise to,

$\mathrm{x}_{\mathrm{i}}=\mathrm{c}_{\mathrm{i}}^{\mathrm{mon}} / \mathrm{f}_{\mathrm{i}}^{\mu} \mathrm{c}_{\mathrm{i}}^{\mu}$ 
where $\mathrm{x}_{\mathrm{i}}$ is the mole fraction of the $\mathrm{i}^{\text {th }}$ component in the micelle, $\mathrm{c}_{\mathrm{i}}^{\text {mon }}$ the monomer concentration of the $\mathrm{i}^{\text {th }}$ component, $\mathrm{f}_{\mathrm{i}}{ }^{\mu}$ its activity coefficient in the micelle, and $\mathrm{c}_{\mathrm{i}}{ }^{\mu}$ its cmc. For a binary mixture this gives rise to the familiar expression for the mixed $\mathrm{cmc}$,

$$
\frac{1}{c_{m i x}^{\mu}}=\frac{\alpha_{1}}{f_{1} c_{1}^{\mu}}+\frac{\alpha_{2}}{f_{2} c_{2}^{\mu}}
$$

The activity coefficients are determined from an expansion of the excess free energy of mixing, Ge, which including quadratic and cubic terms is in the form,

$\mathrm{Ge}=\mathrm{x}_{1} \mathrm{X}_{2} \mathrm{~B}_{12}+\mathrm{x}_{1} \mathrm{x}_{2}\left(\mathrm{x}_{1}-\mathrm{X}_{2}\right) \mathrm{C}_{12}$

where $\mathrm{B}_{12}$ and $\mathrm{C}_{12}$ are the interaction constants (abbreviated to $\mathrm{B}$ and $\mathrm{C}$ in this paper), and abbreviated to $\mathrm{B}$ and $\mathrm{C}$ in the paper. In the Regular Solution Approximation $\mathrm{C}_{12}$ is zero. As described in detail elsewhere $(44,45,49)$ this approach also leads to a set of equations that determine the variation in micelle composition and the variation in surface and monomer concentrations below and above the $\mathrm{cmc}$. For the micelle data $(\mathrm{cmc}$ variation and micelle composition) and the surface data presented here this Pseudo Phase approach has been applied with the additional constraint that the same model parameters are constrained to fit both the solution and surface data.

For the data in figure 1a, the red line is from the analysis using equations 2 and 3 for the $\mathrm{cmc}$ variation, where the data shows a slight departure from ideality. The B of -0.2 is indicative of a small attractive interaction between the SDS and SLES. The variation of the cmc with composition is well described by the Regular Solution approximation, without the need for any higher order terms in the expansion of the excess free energy of mixing which would characterise any asymmetry in the mixing behaviour.

The micelle mixing was also evaluated using SANS. SANS measurements for the isotopic combinations h-SLES / h-SDS and h-SLES / d-SDS in $\mathrm{D}_{2} \mathrm{O}$ were used to directly determine the micelle composition as a function of solution composition and concentration and at different $\mathrm{AlCl}_{3}$ concentrations; as described in more detail in the Supporting Information. The results are compared with the cmc variation and the surface composition and evaluated in the context of the pseudo phase approximation later in the paper,

The surface mixing was evaluated using NR at a surfactant concentration of $2 \mathrm{mM}$, below the mixed cmc in the absence of electrolyte; see figure $1 \mathrm{~b}$ for the variation in surface composition with solution composition. The measurements were made for the three different alkyl chain 
labelled combinations of SDS and SLES in nrw; that is, d-SLES / d-SDS, h-SLES / d-SDS, and d-SLES / h-SDS, abbreviated dd, hd, and dh. The reflectivity data, not shown, are described by a single monolayer of uniform composition, as described in detail elsewhere (7), and are analysed quantitatively to provide a thickness, $d$, and a scattering length density, $\rho$. The product d. $\rho$ is related to the area / molecule, A, or adsorbed amount by d. $\rho=\sum b / A$, where $\sum b$ is the sum of scattering lengths of the component at the interface. The corresponding $\sum \mathrm{b}$ values for $\mathrm{d}$, $\mathrm{h}$ SDS and d, h-SLES are summarised in table S2 in the Supporting Information. For a binary mixture measurement of the three isotopic combinations described earlier gives rise to three simultaneous equations of the form,

$\mathrm{d} \rho=\sum \mathrm{b}_{1} / \mathrm{A}_{1}+\sum \mathrm{b}_{2} / \mathrm{A}_{2}$

and these are solved by least squares for the data tabulated in table S3a in the Supporting Information. The mean thickness of the adsorbed layer is $\sim 21 \pm 2 \AA$ and $\rho$ varies from $\sim 0.2 \mathrm{x}$ $10^{-6}$ to $\sim 3.9 \times 10^{-6} \AA^{-2}$, depending upon the isotopic combination and the solution composition. The variation in surface composition with solution composition at a fixed solution concentration of $2 \mathrm{mM}$ (below the mixed $\mathrm{cmc}$ in the absence of electrolyte) is shown in figure $1 b$, and summarised in table S3b in the Supporting Information. The surface composition shows a slight departure from ideal mixing, and is best described in the Pseudo Phase Approximation framework with the interaction constants $\mathrm{B}=-0.2$ and $\mathrm{C}=-0.4$. Hence there is a small attractive (synergistic) interaction between the SDS and SLES at the surface. The interaction is slightly stronger than in the micelle mixing and is asymmetrical. The mean adsorbed amount shows no significant variation with composition (see table S3 in the Supporting Information) and the mean value is $\sim 3.85 \pm 0.05 \times 10^{-10} \mathrm{~mol} \mathrm{~cm}^{-2}$. This compares with saturation adsorption values for SDS and SLES of $\sim 4.2 \times 10^{-10}$ and $3.6 \times 10^{-10} \mathrm{~mol} \mathrm{~cm}^{-2}$ respectively. It was previously demonstrated (43) that the presence of the ethylene oxide group in the SLES headgroup region resulted in a greater degree of counterion binding in the micelles. Hence it is postulated that the slight synergistic interaction here results from a reduction in the inter-headgroup repulsion arising from the presence of the SLES ethylene oxide group in the surface headgroup region. However, the slight departure from ideal mixing is also consistent with other observations in other anionic surfactant mixtures (44).

\section{(b) Evolution of surface structure in $\mathrm{AlCl}_{3}$ for SLES / SDS mixtures}

The nature of the adsorption and the structure of the adsorbed layer for the SLES / SDS mixtures were measured by $\mathrm{NR}$ at a fixed surfactant concentration of $2 \mathrm{mM}$, for $\mathrm{AlCl}_{3}$ 
concentrations from 0.01 to $2 \mathrm{mM}$ and for SLES / SDS solution compositions of 100/0, 80/20, 60/40, 50/50, 40/60, 20/80 mole ratio. The measurements for $2 \mathrm{mM}$ SLES were previously reported by $\mathrm{Xu}$ et al (24), and are reproduced in this paper. The measurements were made predominantly for the isotopic combinations of d-SLES / d-SDS in nrw. At selected solution compositions and $\mathrm{AlCl}_{3}$ concentrations measurements were also made for the additional isotopic combinations, h-SLES / d-SDS and in some limited cases d-SLES / h-SDS. They are reported here for 80/20 SLES / SDS at 0.05, 0.5 and $1 \mathrm{mM} \mathrm{AlCl}_{3}$ and for 50/50 SLES / SDS at $0.05 \mathrm{mM} \mathrm{AlCl}_{3}$.

The data in table 1 summarises the evolution of the surface structure from monolayer, $\mathrm{S}_{1}$, to monolayer + bilayer, $S_{2}$, to monolayer +2 bilayers, $S_{3}$, and to an extended multilayer structure, $\mathrm{S}_{\mathrm{n}}$

Table 1. Table showing the evolution in surface structure (and solution appearance) with solution composition (mole ratio of SLES / SDS) and $\mathrm{AlCl}_{3}$ concentration at a surfactant concentration of $2 \mathrm{mM}$. (red Entries) solutions are cloudy / precipitated, (black entries) clear solutions, $S_{1}$ : monolayer, $S_{2}:$ monolayer + bilayer, $S_{3}:$ monolayer +2 bilayers, $S_{n}:$ Multilayer.

\begin{tabular}{|c|c|c|c|c|c|c|c|}
\hline \multirow{2}{*}{$\begin{array}{c}\text { AlCl3 } \\
\text { concentration } \\
(\mathbf{m M})\end{array}$} & \multicolumn{7}{|c|}{ SLES / SDS composition } \\
\cline { 2 - 8 } & $\mathbf{1 0 0 / 0}$ & $\mathbf{8 0 / 2 0}$ & $\mathbf{6 0 / 4 0}$ & $\mathbf{5 0 / 5 0}$ & $\mathbf{4 0 / 6 0}$ & $\mathbf{2 0 / 8 0}$ & $\mathbf{0 / 1 0 0}$ \\
\hline 0.0 & $\mathrm{~S}_{1}$ & $\mathrm{~S}_{1}$ & $\mathrm{~S}_{1}$ & $\mathrm{~S}_{1}$ & $\mathrm{~S}_{1}$ & $\mathrm{~S}_{1}$ & $\mathrm{~S}_{1}$ \\
\hline 0.01 & $\mathrm{~S}_{1}$ & $\mathrm{~S}_{1}$ & $\mathrm{~S}_{2}$ & $\mathrm{~S}_{1}$ & $\mathrm{~S}_{1}$ & $\mathrm{~S}_{1}$ & $\mathrm{~S}_{1}$ \\
\hline 0.05 & - & $\mathrm{S}_{2}$ & $\mathrm{~S}_{2}$ & $\mathrm{~S}_{2}$ & $\mathrm{~S}_{2}$ & $\mathrm{~S}_{2}$ & $\mathrm{~S}_{2}$ \\
\hline 0.08 & - & $\mathrm{S}_{2}$ & - & - & - & - & - \\
\hline 0.1 & - & $\mathrm{S}_{2}$ & $\mathrm{~S}_{1}$ & $\mathrm{~S}_{2}$ & $\mathrm{~S}_{2}$ & $\mathrm{~S}_{3}$ & $\mathrm{~S}_{2}$ \\
\hline 0.2 & - & $\mathrm{S}_{1}$ & - & $\mathrm{S}_{1}$ & - & - & - \\
\hline 0.3 & $\mathrm{~S}_{1}$ & $\mathrm{~S}_{1}$ & - & - & $\mathrm{S}_{1}$ & $\mathrm{~S}_{1}$ & $\mathrm{~S}_{3}$ \\
\hline 0.35 & - & - & - & $\mathrm{S}_{1}$ & - & - & - \\
\hline 0.5 & $\mathrm{~S}_{2}$ & $\mathrm{~S}_{1}$ & - & $\mathrm{S}_{\mathrm{n}}$ & $\mathrm{S}_{\mathrm{n}}$ & $\mathrm{S}_{\mathrm{n}}$ & $\mathrm{S}_{\mathrm{n}}$ \\
\hline 0.65 & - & $\mathrm{S}_{1}$ & $\mathrm{~S}_{2}$ & - & - & - & - \\
\hline 0.8 & - & $\mathrm{S}_{\mathrm{n}}$ & $\mathrm{S}_{\mathrm{n}}$ & - & - & - & - \\
\hline 1.0 & $\mathrm{~S}_{\mathrm{n}}$ & $\mathrm{S}_{\mathrm{n}}$ & $\mathrm{S}_{\mathrm{n}}$ & $\mathrm{S}_{\mathrm{n}}$ & $\mathrm{S}_{\mathrm{n}}$ & $\mathrm{S}_{\mathrm{n}}$ & $\mathrm{S}_{\mathrm{n}}$ \\
\hline 2.0 & - & - & $\mathrm{S}_{\mathrm{n}}$ & - & - & - & - \\
\hline
\end{tabular}


The reflectivity data in figure 2 shows the variation in reflectivity (and the corresponding surface structure) with increasing $\mathrm{AlCl}_{3}$ concentration for $2 \mathrm{mM} \mathrm{d}$-SLES / d-SDS at solution compositions of 0 / 100, 20 / 80, 50 / 50, 80 / 20, and 100 / 0.

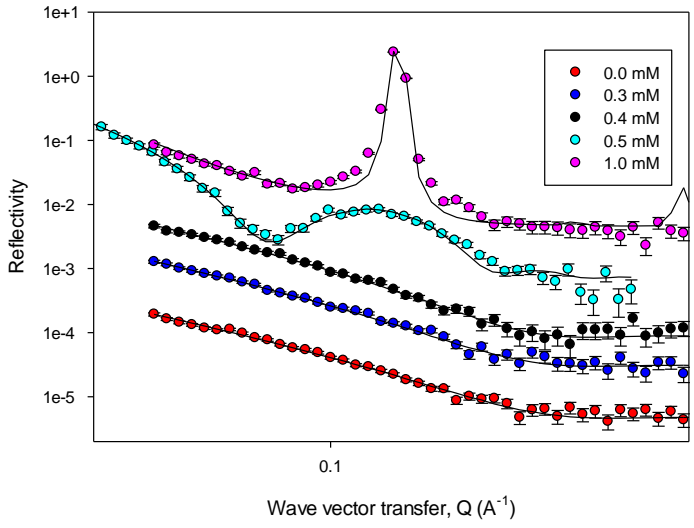

(a)

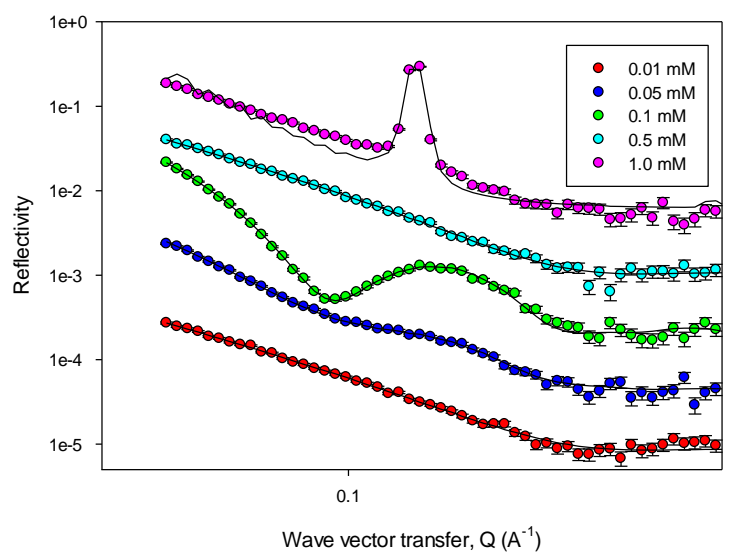

(c)

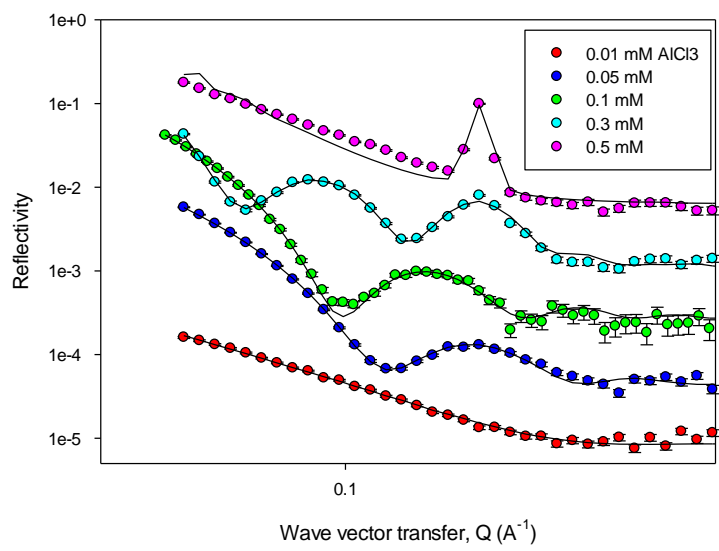

(e)

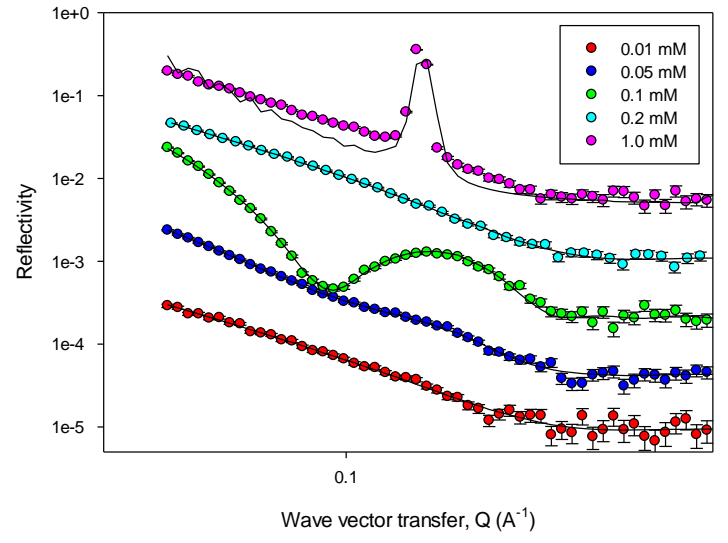

(b)

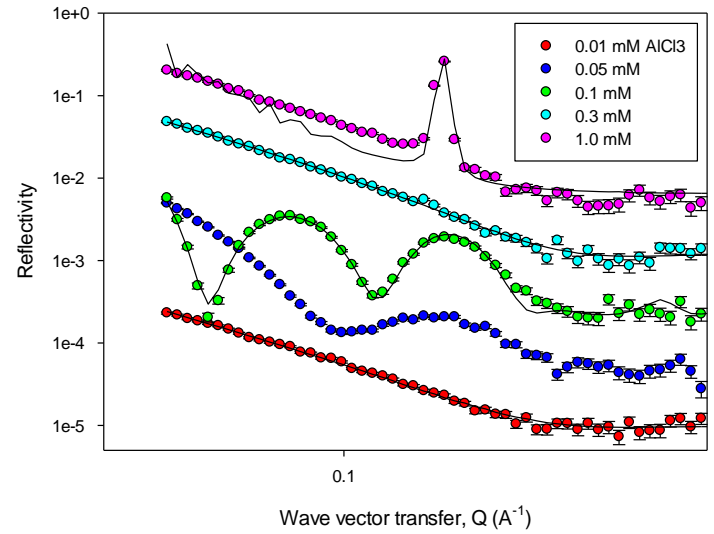

(d) 
Figure 2. Neutron reflectivity versus $Q$ for $2 \mathrm{mM} d$-SLES / $d$-SDS in nrw and increasing $\mathrm{AlCl}_{3}$ concentrations, (a) SLES, (b) 80 / 20 mole ratio SLES / SDS, (c) 50 / 50, (d) 20 / 80, and (e) SDS. Each curve is shifted vertically with respect to the previous curve by a factor $x 5$. The solid lines are model calculations as described in the text with the key model parameters summarised in table 2. The data for $2 \mathrm{mM}$ SLES are reproduced from reference 22. See legend for details of the $\mathrm{AlCl}_{3}$ concentrations.

Table 2. Key model parameters for the reflectivity data in figure 2, for d-SLES / d-SDS / AlCl 3 .

(a) SLES

\begin{tabular}{|c|c|c|c|c|c|c|}
\hline $\begin{array}{c}\mathrm{AlCl}_{3} \\
\text { concentration } \\
(\mathrm{mM})\end{array}$ & $d_{1}( \pm 1 \AA)$ & $\begin{array}{c}\rho_{1}\left( \pm 0.1 \times 10^{-6}\right. \\
\left.\AA^{-2}\right)\end{array}$ & $d_{2}( \pm 1 \AA)$ & $\begin{array}{c}\rho_{2}( \pm 0.1 \times 10 \\
\left.{ }^{6} \AA^{-2}\right)\end{array}$ & $d_{3}( \pm 1 \AA)$ & $\begin{array}{c}\rho_{3}( \pm 0.1 \times 10 \\
\left.{ }^{6} \AA^{-2}\right)\end{array}$ \\
\hline 0.0 & 21 & 2.8 & - & - & - & - \\
\hline 0.3 & 23 & 2.5 & - & - & - & - \\
\hline 0.4 & 23 & 2.6 & - & - & - & - \\
\hline 0.5 & 19 & 3.2 & 17 & 0.7 & 31 & 3.5 \\
\hline & $d_{1}( \pm 0.5 \AA)$ & $d_{2}( \pm 0.5 \AA)$ & $\begin{array}{c}\rho_{1}( \pm 0.1 \times 10 \\
\left.{ }^{6} \AA^{-2}\right)\end{array}$ & $\begin{array}{c}\rho_{2}( \pm 0.1 \times 10 \\
\left.{ }^{6} \AA^{-2}\right)\end{array}$ & $\mathbf{n}$ & $\Delta Q / Q$ \\
\hline 0.8 & 23 & 24 & 2.9 & 0.6 & 40 & 0.07 \\
\hline
\end{tabular}

(b) $80 / 20$ mole ratio SLES / SDS

\begin{tabular}{|c|c|c|c|c|c|c|}
\hline $\begin{array}{c}\mathrm{AlCl}_{3} \\
\text { concentration } \\
(\mathbf{m M})\end{array}$ & $d_{1}( \pm 1 \AA)$ & $\begin{array}{c}\rho_{1}\left( \pm 0.1 \times 10^{-6}\right. \\
\left.\AA^{-2}\right)\end{array}$ & $d_{2}( \pm 1 \AA)$ & $\begin{array}{c}\rho_{2}\left( \pm 0.1 \times 10^{-}\right. \\
\left.{ }^{6} \AA^{-2}\right)\end{array}$ & $d_{3}( \pm 1 \AA ̊)$ & $\begin{array}{c}\rho_{3}\left( \pm 0.1 \times 10^{-}\right. \\
\left.{ }^{6} \AA^{-2}\right)\end{array}$ \\
\hline 0.01 & 21 & 3.4 & - & - & - & - \\
\hline 0.05 & 19 & 4.5 & 39 & 0.9 & - & - \\
\hline 0.1 & 25 & 4.4 & 11 & 0.6 & 27 & 3.2 \\
\hline 0.5 & 20 & 3.7 & - & - & - & - \\
\hline & $d_{1}( \pm 0.5 \AA)$ & $d_{2}( \pm 0.5 \AA)$ & $\begin{array}{c}\rho_{1}\left( \pm 0.1 \times 10^{-}\right. \\
\left.{ }^{6} \AA^{-2}\right)\end{array}$ & $\begin{array}{c}\rho_{2}( \pm 0.1 \times 10 \\
\left.{ }^{6} \AA^{-2}\right)\end{array}$ & $\mathbf{n}$ & $\Delta Q / Q$ \\
\hline 1.0 & 25 & 24 & 2.8 & \begin{tabular}{ll|}
1.8 \\
\end{tabular} & 20 & 0.05 \\
\hline
\end{tabular}


(c) 50 / 50 mole ratio SLES / SDS

\begin{tabular}{|c|c|c|c|c|c|c|}
\hline $\begin{array}{c}\mathrm{AlCl}_{3} \\
\text { concentration } \\
(\mathrm{mM})\end{array}$ & $d_{1}( \pm 1 \AA)$ & $\begin{array}{c}\rho_{1}\left( \pm 0.1 \times 10^{-6}\right. \\
\left.\AA^{-2}\right)\end{array}$ & $\mathrm{d}_{2}( \pm 1 \AA)$ & $\begin{array}{c}\rho_{2}\left( \pm 0.1 \times 10^{-}\right. \\
\left.{ }^{6} \AA^{-2}\right)\end{array}$ & $d_{3}( \pm 1 \AA)$ & $\begin{array}{c}\rho 3( \pm 0.1 \times 10 \\
\left.{ }^{6} \AA^{-2}\right)\end{array}$ \\
\hline 0.01 & 22 & 3.4 & - & - & - & - \\
\hline 0.05 & 27 & 3.8 & 16 & 0.6 & 23 & 0.8 \\
\hline 0.1 & 21 & 4.7 & 16 & 0.6 & 22 & 3.3 \\
\hline 0.2 & 21 & 4.1 & - & - & - & - \\
\hline & $d_{1}( \pm 0.5 \AA)$ & $d_{2}( \pm 0.5 \AA)$ & $\begin{array}{c}\rho_{1}\left( \pm 0.1 \times 10^{-}\right. \\
\left.{ }^{6} \AA^{-2}\right)\end{array}$ & $\begin{array}{c}\rho_{2}\left( \pm 0.1 \times 10^{-}\right. \\
\left.{ }^{6} \AA^{-2}\right)\end{array}$ & $\mathrm{n}$ & $\Delta \mathbf{Q} / \mathbf{Q}$ \\
\hline 1.0 & 24 & 23 & 2.8 & 1.8 & 20 & 0.05 \\
\hline
\end{tabular}

(d) 20/80 mole ratio SLES / SDS

\begin{tabular}{|c|c|c|c|c|c|c|c|c|c|c|}
\hline $\begin{array}{c}\mathrm{AlCl}_{3} \\
\text { concentratio } \\
\mathbf{n}(\mathbf{m M})\end{array}$ & $\begin{array}{l}\mathrm{d}_{1} \\
( \pm 1 \\
\AA\end{array}$ & $\begin{array}{c}\rho_{1} \\
( \pm 0.1 \times 1 \\
\left.0^{-6} \AA^{-2}\right)\end{array}$ & $\begin{array}{c}\mathbf{d}_{2}(\mathbf{\pm 1} \\
\AA\end{array}$ & $\begin{array}{c}\rho_{2} \\
( \pm 0.1 \times 1 \\
\left.0^{-6} \AA^{-2}\right)\end{array}$ & $\begin{array}{l}\mathbf{d}_{3} \\
( \pm \\
\mathbf{1} \\
\AA)\end{array}$ & $\begin{array}{c}\rho_{3} \\
( \pm 0.1 \times 1 \\
\left.0^{-6} \AA^{-2}\right)\end{array}$ & $\begin{array}{l}d_{4} \\
( \pm\end{array}$ & $\begin{array}{c}\rho_{4} \\
( \pm 0.1 \times 1 \\
\left.0^{-6} \AA^{-2}\right)\end{array}$ & $\begin{array}{l}\text { d5 } \\
( \pm \\
1 \\
\AA \\
\AA\end{array}$ & $\begin{array}{c}\rho_{5} \\
( \pm 0.1 \times 1 \\
\left.0^{-6} \AA^{-2}\right)\end{array}$ \\
\hline 0.01 & 21 & 3.1 & - & - & - & - & - & - & - & - \\
\hline 0.05 & 24 & 4.7 & 9 & 1.1 & 25 & 2.8 & - & - & - & - \\
\hline 0.1 & 26 & 3.8 & 7 & 0.6 & 33 & 3.9 & 11 & 0.6 & 24 & 4.3 \\
\hline \multirow[t]{2}{*}{0.5} & 20 & 3.7 & - & - & - & - & - & - & - & - \\
\hline & $\begin{array}{c}d_{1} \\
( \pm 0 . \\
5 \text { A) }\end{array}$ & $\begin{array}{c}\mathrm{d}_{2}(\mathbf{\pm 0 . 5} \\
\stackrel{\circ}{\mathrm{A}})\end{array}$ & $\begin{array}{c}\rho 1 \\
( \pm 0.1 \times 1 \\
\left.0^{-6} \AA^{-2}\right)\end{array}$ & $\begin{array}{c}\rho_{2} \\
( \pm 0.1 \times 1 \\
\left.0^{-6} \AA^{-2}\right)\end{array}$ & $\mathbf{n}$ & $\Delta \mathbf{Q} / \mathbf{Q}$ & & & & \\
\hline 1.0 & 22 & 21 & 3.5 & 2.5 & 30 & 0.04 & & & & \\
\hline
\end{tabular}


(e) SDS

\begin{tabular}{|c|c|c|c|c|c|c|c|c|c|c|}
\hline $\begin{array}{c}\mathrm{AlCl}_{3} \\
\text { concentratio } \\
\mathbf{n}(\mathbf{m M})\end{array}$ & $\begin{array}{l}d_{1} \\
( \pm 1 \\
\AA\end{array}$ & $\begin{array}{c}\rho_{1} \\
( \pm 0.1 \times 1 \\
\left.0^{-6} \AA^{-2}\right)\end{array}$ & $\begin{array}{c}\mathbf{d}_{2}(\mathbf{( 1} \\
\stackrel{\AA}{\mathrm{A}})\end{array}$ & $\begin{array}{c}\rho_{2} \\
( \pm 0.1 \times 1 \\
\left.0^{-6} \AA^{-2}\right)\end{array}$ & $\begin{array}{l}d_{3} \\
( \pm \\
1 \\
\text { A) }\end{array}$ & $\begin{array}{c}\rho_{3} \\
( \pm 0.1 \times 1 \\
\left.0^{-6} \AA^{-2}\right)\end{array}$ & $\begin{array}{l}d_{4} \\
( \pm \\
1 \\
\text { Å) }\end{array}$ & $\begin{array}{c}\rho 4 \\
( \pm 0.1 \times 1 \\
\left.0^{-6} \AA^{-2}\right)\end{array}$ & $\begin{array}{l}\text { d5 } \\
( \pm \\
1 \\
\AA \\
\mathbf{A})\end{array}$ & $\begin{array}{c}\rho_{5} \\
( \pm 0.1 \times 1 \\
\left.0^{-6} \AA^{-2}\right)\end{array}$ \\
\hline 0.01 & 22 & 2.7 & - & - & - & - & - & - & - & - \\
\hline 0.05 & 19 & 5.9 & 4 & 0.2 & 27 & 4.8 & - & - & - & - \\
\hline 0.1 & 31 & 4.8 & 13 & 0.6 & 39 & 3.8 & - & - & - & - \\
\hline \multirow[t]{2}{*}{0.3} & 19 & 5.4 & 8 & 0.3 & 31 & 4.4 & 4 & 0.3 & 27 & 4.0 \\
\hline & $\begin{array}{c}d_{1} \\
( \pm 0 . \\
5 \AA\end{array}$ & $\begin{array}{c}\mathrm{d}_{2}(\mathbf{\pm 0 . 5} \\
\stackrel{\circ}{\mathrm{A}})\end{array}$ & $\begin{array}{c}\rho_{1} \\
( \pm 0.1 \times 1 \\
\left.0^{-6} \AA^{-2}\right)\end{array}$ & $\begin{array}{c}\rho_{2} \\
( \pm 0.1 \times 1 \\
\left.0^{-6} \AA^{-2}\right)\end{array}$ & $\mathbf{n}$ & $\Delta Q / Q$ & & & & \\
\hline 0.5 & 20 & 18 & 3.7 & 2.9 & 30 & 0.07 & & & & \\
\hline
\end{tabular}

The data summarised in table 1 , and for which a subset is shown in figure 2, are mostly analysed using the exact optical matrix approach in thin film optics $(7,43)$. The simplest model (least number of layers) consistent with the data is used, and interfacial roughness is not included. The forms of the reflectivity and the associated surface structures observed are broadly consistent with those previously reported for the SLES (23-25) and MES (27-29) surfactants. However the detailed variations with $\mathrm{AlCl}_{3}$ are different and are discussed in more detail later. The reflectivity data in the absence of electrolyte and at low $\mathrm{AlCl}_{3}$ concentrations are in the form of a monotonic curve, consistent with monolayer adsorption, $\mathrm{S}_{1}$ structure, at the interface. As discussed earlier in the context of the SLES / SDS surface mixing, these data are consistent with a single uniform layer, described by a thickness, $\mathrm{d}$, and a scattering length density, $\rho$; and which enable an evaluation of the adsorbed amount to be made. For monolayer adsorption the thickness and scattering length density of the monolayer are referred to a $\mathrm{d}$ and $\rho$ in table $\mathrm{S} 3$, and as $\mathrm{d}_{1}$ and $\rho_{1}$ in the monolayer regions in tables 2 and $\mathrm{S} 4$. At higher $\mathrm{AlCl}_{3}$ concentrations the data are characterised by a single broad interference fringe with a minimum at a $\mathrm{Q}$ value $\sim 0.1 \AA^{-1}$. This is consistent with the $\mathrm{S}_{2}$ structure, and is well described by three layers; corresponding to an initial monolayer at the air-water interface with a surfactant bilayer beneath and separated from the initial monolayer by a relatively thin hydrated headgroup region (referred to $d_{1}, d_{2}$ and $d_{3}$ in tables 2 and $\mathrm{S} 4$ ). The data showing a more complex reflectivity profile at slightly higher $\mathrm{AlCl}_{3}$ concentration, observed here only at the more SDS rich compositions of $80 / 20$ and 100 / 0, with a double interference fringe. are consistent with five layers, $S_{3}$ structure (referred to as $d_{1}$ to $d_{5}$ in tables 2 and $S 4$ ). This is equivalent to an initial 
monolayer with two bilayers adsorbed beneath the initial monolayer, as observed and described elsewhere for some related systems $(24,25,27)$. At the highest $\mathrm{AlCl}_{3}$ concentrations the data are characterised by a single relatively sharp Bragg peak, at a $Q \sim 0.15 \AA^{-1}$. This corresponds to an extended multilayer structure at the interface and is analysed quantitatively using a surface multilayer model based on the kinematic approximation $(54,55)$. The structure is characterised by multiple bilayers with a bilayer thickness, $d_{t}$, comprising of $d_{1}+d_{2}$, where $d_{1}$ and $d_{2}$ are the overlapping alkyl chain and hydrated headgroup regions of the bilayer, $\rho_{1}$ and $\rho_{2}$ are the corresponding scattering length densities of the two regions in the bilayer, $\mathrm{n}$ is the number of bilayers, and $\Delta \mathrm{Q} / \mathrm{Q}$ is a resolution term. As there is usually only a single Bragg peak visible and an absence of interference fringes arising from the total thickness at the interface, $\mathrm{n}$ is generally large, $>10$. However this would also result in a Bragg peak that is too narrow compared to that observed, the Bragg peak width is $\infty 1 / \mathrm{n}$, and the $\Delta \mathrm{Q} / \mathrm{Q}$ term broadens the Bragg peak and dampens the higher frequency interference fringes. $\Delta \mathrm{Q}$ is usually larger than the instrumental resolution, which here is $\sim 4 \%$ in $\Delta \mathrm{Q} / \mathrm{Q}$, and the additional contribution is associated with a surface mosaic spread of the laterally inhomogeneous surface multilayer structure. In the data presented here $\Delta \mathrm{Q} / \mathrm{Q}$ typically varies from 0.04 to 0.07 . The parameters summarised in table 2 are broadly consistent with those previously reported for SLES (23-25). However, a notable trend in the bilayer thickness, $\mathrm{d}_{\mathrm{t}}$, is observed as the solution composition varies from SLES rich to SDS rich. That is, the bilayer thickness varies from $\sim 47 \AA$ for SLES rich compositions to $\sim 40 \AA$ for SDS rich, reflecting directly the impact of the decreasing headgroup size from SLES to SDS.

For the SLES / SDS mixtures only there is a region before the multilayer formation where the surface structure, over a limited but finite $\mathrm{AlCl}_{3}$ concentration range, reverts to a monolayer.

The data summarised in table 1 are presented as a surface phase diagram in figure 3. 


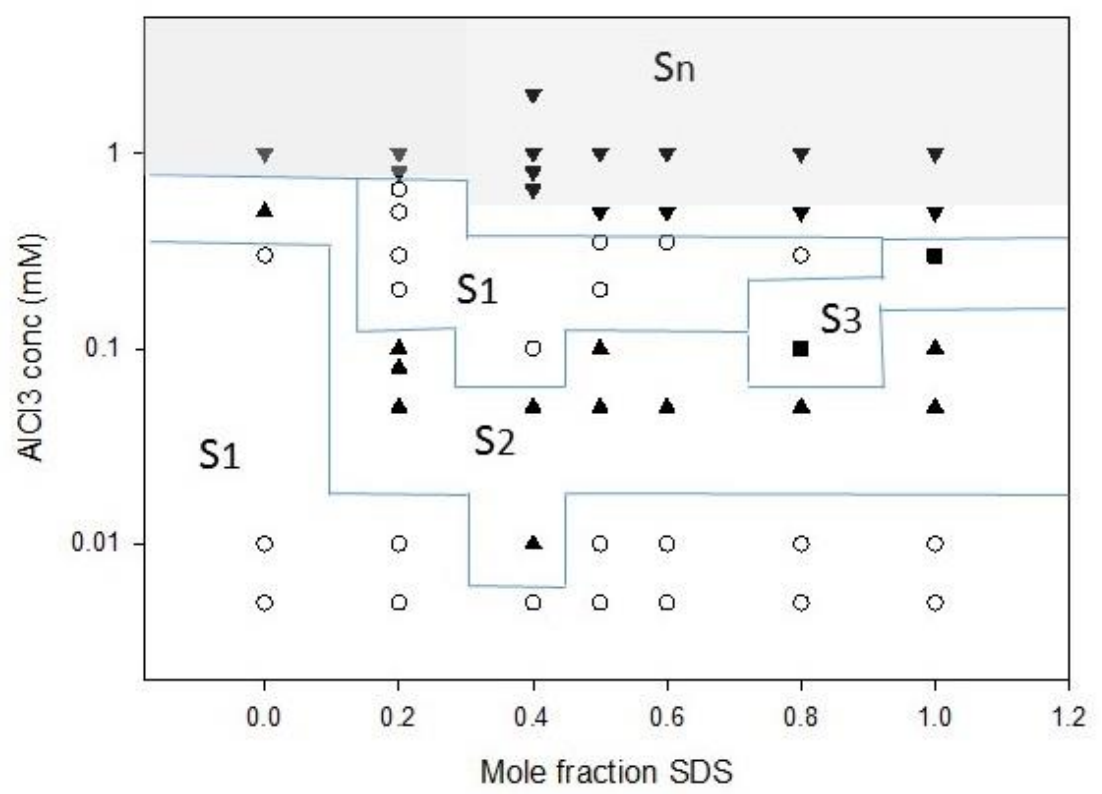

Figure 3. Surface phase diagram for SLES / SDS in $\mathrm{AlCl}_{3}$ at a surfactant concentration of 2 $m M$, for AlCl $\mathrm{Al}_{3}$ concentrations versus mole fraction of SDS in solution: (o) $S_{1},(\mathbf{\Delta}) S_{2}$, (匹) $S_{3}$, and $(\boldsymbol{\nabla}) S_{n}$. The differently shaded areas show the regions in which the solutions are clear, cloudy, or show signs of precipitation.

The data trends in figure 2 and the surface phase diagram in figure 3 for the SLES / SDS mixtures in $\mathrm{AlCl}_{3}$ illustrate some interesting features and trends which are summarised as follows:

(i) The variation in the surface structure with increasing $\mathrm{AlCl}_{3}$ concentration is broadly similar to that observed for SLES (and MES). That is, with increasing $\mathrm{AlCl}_{3}$ concentration the surface exhibits an increasing degree or extent of layering, from $S_{1}$ to $S_{2}$, to often $S_{3}$ to $S_{5}$ (depending upon the surfactant type and surfactant concentration), and ultimately to $\mathrm{S}_{\mathrm{n}}$.

(ii) For SLES there is a transition from $S_{1}$ to $S_{2}$ to $S_{n}$. However for SDS there is an intermediate structure, $S_{3}$, between $S_{2}$ and $S_{n}$ at the richer $S D S$ solution compositions.

(iii) For SLES the transition from monolayer, $\mathrm{S}_{1}$, to the more ordered structures occurs for $\mathrm{AlCl}_{3}$ concentrations $\geq 0.5 \mathrm{mM}$. Once SDS is added to the solution this initial transition decreases by an order of magnitude in $\mathrm{AlCl}_{3}$ concentration to $\sim 0.05 \mathrm{mM}$; and this is relatively independent of the SLES / SDS solution composition. This is 
consistent with the observations of Xu et al (24) for the SLES surface ordering in $\mathrm{AlCl}_{3}$ with varying ethylene oxide group from 1 to 3 units. This resulted in the onset of surface layering occuring at increasingly larger $\mathrm{AlCl}_{3}$ as the number of ethylene oxide groups increased at a fixed surfactant concentration. Indeed the transition from $S_{1}$ to $S_{2}$ for SDS and SLES (with one ethylene oxide group) occurs at similar $\mathrm{AlCl}_{3}$ concentrations.

(iv) For the pure SDS and SLES solutions the surface evolves to one of increasingly extended multilayer formation as the $\mathrm{AlCl}_{3}$ concentration increases. This is generally what is observed in the different SLES and MES systems studied (23-25, 27-29). However, it is notable that for the SLES / SDS mixtures in the $\mathrm{AlCl}_{3}$ concentration range $\sim 0.1$ to $0.5 \mathrm{mM}$ there is a region where the surface structure reverts to a monolayer before at even higher $\mathrm{AlCl}_{3}$ concentrations the extended multilayer structures, $S_{n}$, occur. This has not been observed in other systems, and is unexpected. It is discussed in more detail later in the paper.

(v) As shown in table 1 and figure 3 the onset of surface layering occurs generally outside the regime of precipitation, and this was a general observation of Thomas and Penfold (19) in reviewing the results from a wide range of similar systems. Here an important further observation from the trends in table 1 and figure 3 is that for the SLES / SDS mixtures the transition from a layered structure, generally $S_{2}$ or $S_{3}$, back to a monolayer as $\mathrm{AlCl}_{3}$ concentration is increased is not associated with the effects of precipitation.

\section{(c) Variation in surface composition in $\mathrm{AlCl}_{3}$}

The reflectivity data for the SLES / SDS compositions of 80 / 20 and 50 / 50 were measured for the isotopic combinations of $\mathrm{dd}$, hd, and for $\mathrm{dh}$ at some limited $\mathrm{AlCl}_{3}$ concentrations; for 0.01, 0.05, 0.5 and 1.0 $\mathrm{mM}$ for $80 / 20$, and for 0.01 and $0.05 \mathrm{mM}$ for $50 / 50$. The corresponding data for 80 / 20 SLES / SDS in 0.05 and $1.0 \mathrm{mM} \mathrm{AlCl}_{3}$ and for 50 / 50 SLES / SDS in 0.05 $\mathrm{mM} \mathrm{AlCl} 3$ are shown in figure 4. The key model parameters are summarised in table S4 in the Supporting Information. 


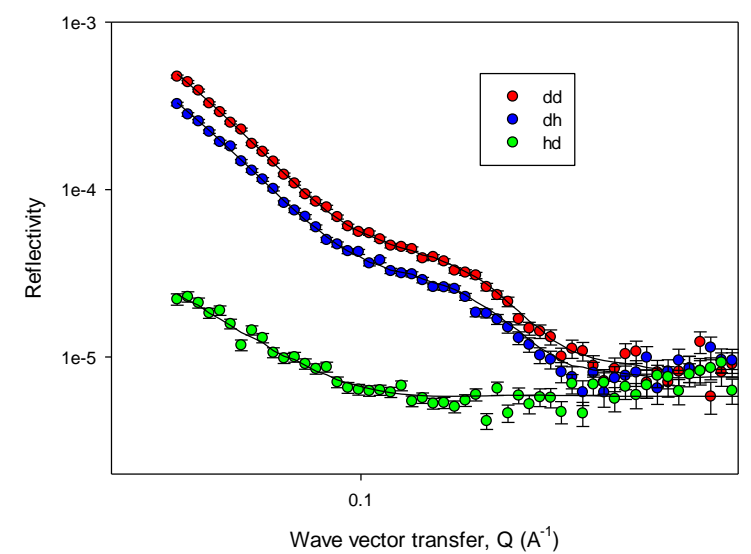

(a)

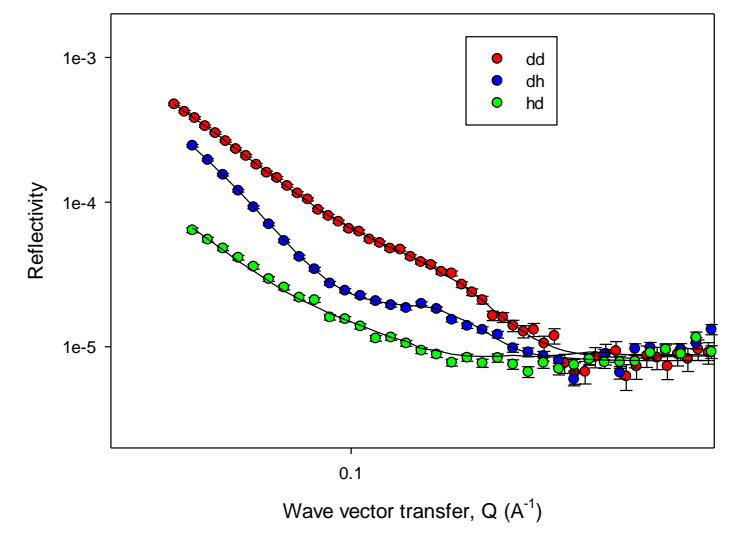

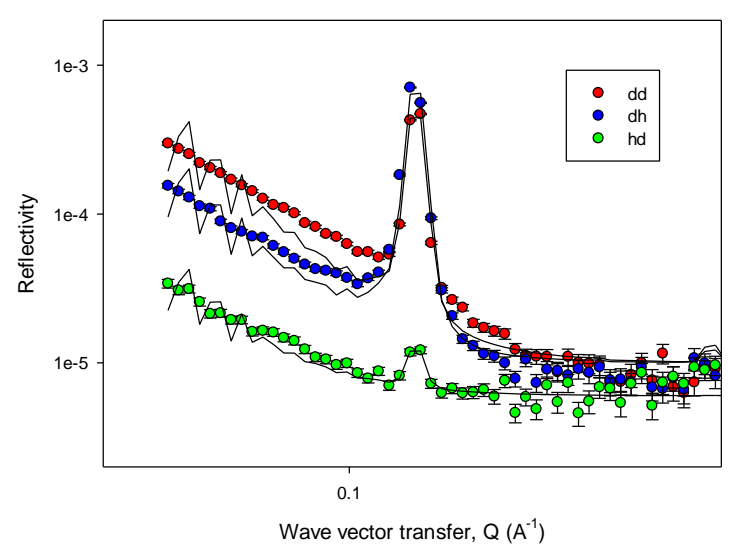

(b)

(c)

Figure 4. Neutron Reflectivity for $2 \mathrm{mM}$ SLES / SDS versus Q for (a) 80/20 SLES / SDS in 0.05 mM AlCl, , (b) 80 / $20 \mathrm{SLES} / \mathrm{SDS}$ in $1.0 \mathrm{mM} \mathrm{AlCl}_{3}$, and (c) 50 / $50 \mathrm{SLES} / \mathrm{SDS}$ in $0.05 \mathrm{mM}$ $\mathrm{AlCl}_{3}:(\bullet) d d$, (o) $h d$, and (4) dh isotopic combinations. The solid lines are model fits as described in earlier in the text and for the key model parameters in table S4 in the Supporting Information.

Some additional measurements were also made for the isotopic combinations dd, hd for 80 / $20 \mathrm{SLES} / \mathrm{SDS}$ at $0.1 \mathrm{mM} \mathrm{AlCl}_{3}$, and for 50 / $50 \mathrm{SLES} / \mathrm{SDS}$ in 0.1 and $1.0 \mathrm{mM} \mathrm{AlCl}_{3}$, and the data are not shown here. The data presented in figure 4 and table S4 show the same surface structure independent of the isotopic labelling. From the model fits for the differently isotopically labelled data an estimate of the surface composition in the initial monolayer, the bilayer and in the multilayer structures can be obtained. The only exception in the data presented is the hd contrast for the 80/20 SLES / SDS in $0.05 \mathrm{mM} \mathrm{AlCl}_{3}$ where the reflectivity is relatively low due to the low fraction of SDS at the interface and in that case the data can be 
adequately modelled as a single layer. For the data where the isotopic combinations of dd, hd, and dh were measured the composition of the monolayer, bilayer and multilayer were determined by least squares, as described previously, using the parameters in table S4. For the data with measurements of the isotopic combinations of $\mathrm{dd}$ and hd, the compositions were determined by solving the corresponding pairs of simultaneous equations, as described earlier in the absence of electrolyte. The variations in the surface compositions in the monolayer, bilayer and multilayer regions of the surface structures are summarised in table S4 in the Supporting Information. The corresponding data for the monolayer and bilayer compositions are shown in figure 5 .

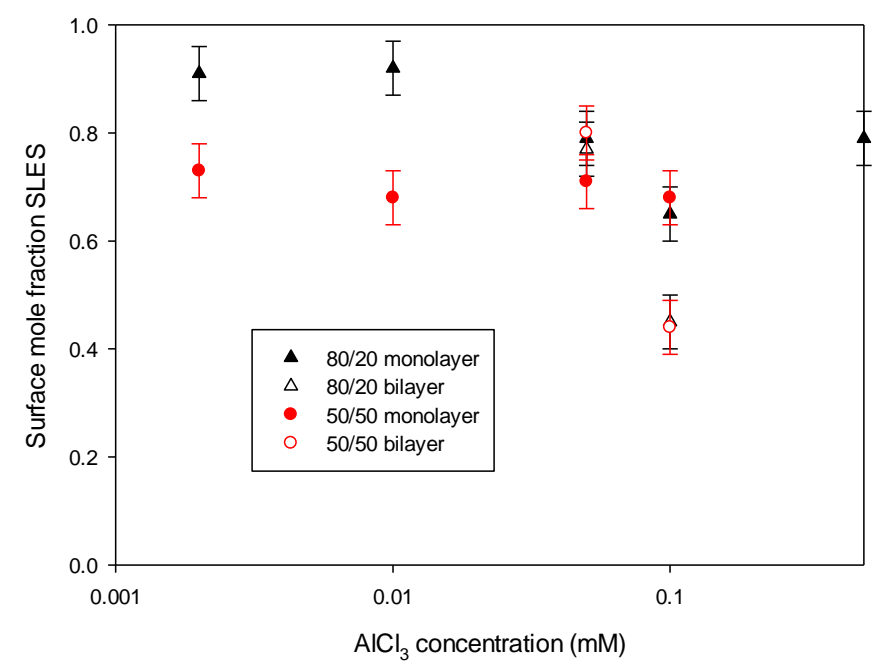

Figure 5. Surface composition (mole fraction SLES) versus AlCl 3 concentration for 80 / 20 $\operatorname{SLES} / \operatorname{SDS}(\mathbf{\Delta}, \triangle)$ and $50 / 50 \operatorname{SLES} / \operatorname{SDS}(\bullet$, o); ( $\mathbf{\Delta}, \bullet)$ for monolayer compositions of monolayer only, $S_{1}$, and initial monolayer in $S_{2}$ structure, and $(\Delta, o)$ for bilayer composition in $S_{2}$ structures.

As discussed earlier the surface in the absence of $\mathrm{AlCl}_{3}$ is generally richer in SLES than the solution composition over most of the solution composition range. In the presence of $\mathrm{AlCl}_{3}$ for the monolayer, in regions where monolayer adsorption still occurs and for the initial monolayer of the $S_{2}$ structure, the general trend is that the amount of SLES at the surface decreases as the $\mathrm{AlCl}_{3}$ concentration increases. For the $\mathrm{AlCl}_{3}$ concentrations where the $\mathrm{S}_{2}$ structure exists, the surface mole fraction of SLES in the bilayer also decreases with increasing $\mathrm{AlCl}_{3}$ concentration. For both the 80 / 20 and 50 / 50 SLES / SDS compositions with $0.05 \mathrm{mM}$ added $\mathrm{AlCl}_{3}$ the bilayer formation is relatively weak and the bilayer now has a composition similar to 
the initial monolayer. However at the higher $\mathrm{AlCl}_{3}$ concentration of $0.1 \mathrm{mM}$, where the bilayer structure is more prominent, the bilayer composition is now significantly richer in SDS. The same trend exists for the bilayer composition in the regions at higher $\mathrm{AlCl}_{3}$ concentrations where the extended multilayer structure, $\mathrm{S}_{\mathrm{n}}$, exists. However, apart from the highest $\mathrm{AlCl}_{3}$ concentration, the surface still remains rich in SLES relative to SDS.

The trend towards a greater fraction of SDS at the surface with added $\mathrm{AlCl}_{3}$ in the more extended layered structures at the interface is consistent with the greater tendency at the surface to bridge $\mathrm{Al}^{3+}$ ions between neighbouring SDS molecules compared to the bulkier SLES molecules. It also may reflect a change in the relative binding strengths of $\mathrm{Na}^{+}$and $\mathrm{Al}^{3+}$ to the different headgroups, and due to the environment of the mixed headgroups. These changes must also be reflected in changes in the bulk micelle and hence monomer compositions that are in equilibrium with the surface. We will return to these points in the next section and later in the discussion when the complementary SANS data are presented and discussed.

\section{(d) Micelle composition and structure}

The variation in surface composition and $\mathrm{cmc}$ in the absence of electrolyte was determined using NR and ST, and analysed using the PPA as described and discussed earlier in the paper. The data are consistent with a slight departure from ideal mixing, see figure 1 , to provide a small asymmetrical attractive and synergistic interaction. To complement that data the micelle compositions have been measured directly using SANS. From the scattering from the isotopic combinations h-SLES / h-SDS and h-SLES / d-SDS in $\mathrm{D}_{2} \mathrm{O}$ the micelle compositions can be determined, as described in detail in the Supporting Information. The SANS measurements were made at surfactant concentrations of 2,5 and $10 \mathrm{mM}$, at solution compositions (mole fraction SLES) of 0.8, 0.6 and 0.2 in absence of electrolyte, and in $\mathrm{AlCl}_{3}$ concentrations from 0.05 to $1.0 \mathrm{mM}$. The data are summarised in table S5 in the Supporting Information. The scope of the data in the absence of electrolyte is limited to SLES rich solution compositions $(\geq 0.5$ mole fraction SLES) due to the proximity of the mixed cmc. In $\mathrm{AlCl}_{3}$ the cmc is significantly reduced, but in that case the composition / concentration range over which the data could be evaluated is also limited due to the onset of precipitation at the lower surfactant concentrations and for the SDS richer solution compositions.

The variation in micelle composition with solution composition and concentration, in the absence of electrolyte, is summarised in table S5a. At the lowest surfactant concentration, 5 $\mathrm{mM}$, the micelle is richer in SLES compared to the solution compositions, and becomes slightly 
richer in SDS as the solution concentration increases. This is entirely consistent with the broad trends of the PPA. Table S5c shows a comparison between the micelle and surface compositions, and within experimental error the two are very similar. Analysis, using the PPA as described earlier, provides a consistent set of interaction parameters for the cmc variation, and the surface and micelle composition variations. The parameters, highlighted previously as $\mathrm{B}=-0.2$ and $=-0.4$, adequately describe all the data. This was illustrated in figure 1 for the $\mathrm{cmc}$ variation and the surface composition. It further illustrated in figure S5 in the Supporting Information where the variation in micelle composition is compared to the PPA calculation. Vora et al (56) reported an interaction parameters, $\mathrm{B}, \sim 0.0$ from the cmc variation of a mixture of SDS and LAS, consistent with or close to ideal mixing

In table S5b in the Supporting Information the ratio of Intensities, $\left.R=I_{h h}(Q) / I_{h d} Q\right)$, in the presence of $\mathrm{AlCl}_{3}$ are summarised. The data show that in the presence of $\mathrm{AlCl}_{3}$ the micelle composition is not changing significantly with $\mathrm{AlCl}_{3}$ or surfactant concentration. Hence due to the modest departure from ideality, the relative closeness of the cmc's of the pure component surfactants, with and without electrolyte, the variations in the solution and surface compositions are relatively small. Hence the addition of $\mathrm{AlCl}_{3}$ has relatively little impact upon the micelle composition.

Over most of the solution concentration and composition and $\mathrm{AlCl}_{3}$ concentration range for the SLES / SDS mixtures explored using SANS the data are consistent with the scattering from globular interacting micelles. The data were quantitatively analysed using the Hayter-Penfold model (47) for interacting micelles, as described in detail in the Supporting Information. From the constrained model fits to the SANS data the key model parameters are the micelle aggregation number, $v$, the charge on the micelle, $\mathrm{z}$, (or degree of ionisation $\delta=\mathrm{z} / \mathrm{v}$ ) and the ellipticity, ee. The SANS data in figure 6 are for $5 \mathrm{mM}$ 60/40 mole ratio SLES / SDS, in $\mathrm{AlCl}_{3}$ concentrations from 0.0 to $1.0 \mathrm{mM}$, and for the isotopic combinations of h-SLES / h-SDS and h-SLES / d-SDS in $\mathrm{D}_{2} \mathrm{O}$; and are representative of the data obtained over the surfactant concentration and composition and $\mathrm{AlCl}_{3}$ concentration ranges explored. The equivalent data for 60 / 40 mole ratio SLES / SDS at $10 \mathrm{mM}$ surfactant concentration are shown in figure S6 in the Supporting Information. 

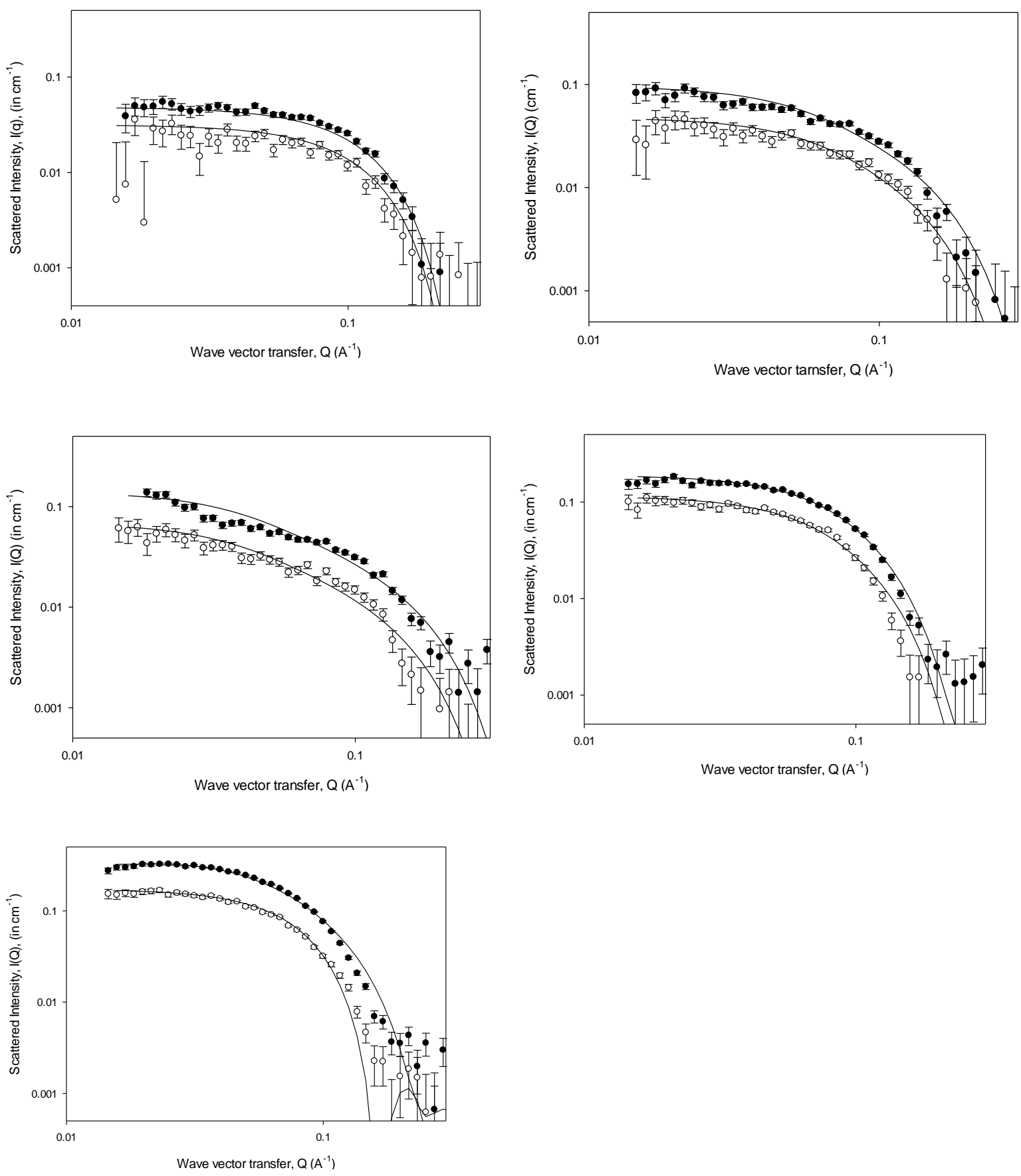

Figure 6. SANS data for $5 \mathrm{mM}$ 60/40 mole ratio SLES / SDS in AlCl 3 concentrations (a) 0.0, (b) $0.05 \mathrm{mM}$, (c) $0.1 \mathrm{mM}$, (d) $0.5 \mathrm{mM}$ and (e) $1.0 \mathrm{mM}$, for (o) hh and (•) hd. The solid lines are model calculations as described in the text and for the key model parameters summarised in table $3 a$. 
Table 3. Key model parameters for core-shell model of interacting micelles for 60/40 mole ratio SLES / SDS.(values are mean values from analysis of $h$, hd data, for comparison of $h h$ and hd model parameters for $10 \mathrm{mM}$ SLES / SDS 60/40 mole ratio see table S6 in the Supporting Information)

(a) $5 \mathrm{mM}$

\begin{tabular}{|c|c|c|c|c|}
\hline $\begin{array}{c}\mathrm{AlCl}_{3} \\
\text { concentration } \\
(\mathrm{mM})\end{array}$ & $v$ & $z( \pm 6)$ & $\operatorname{ext}( \pm 0.2)$ & ee $( \pm 0.07)$ \\
\hline 0.0 & $77( \pm 10)$ & 0 & 1.0 & 1.30 \\
\hline 0.05 & 87 & 0 & 0.7 & 4.00 \\
\hline 0.1 & 116 & 0 & 0.7 & 6.23 \\
\hline 0.5 & $134( \pm 20)$ & 0 & 1.0 & 2.26 \\
\hline 1.0 & 165 & 17 & 1.0 & 2.77 \\
\hline
\end{tabular}

(b) $10 \mathrm{mM}$

\begin{tabular}{|c|c|c|c|c|}
\hline $\begin{array}{c}\mathrm{AlCl}_{3} \\
\text { concentration } \\
(\mathrm{mM})\end{array}$ & $v( \pm 5)$ & $z( \pm 4)$ & $\operatorname{ext}( \pm 0.1)$ & ee $( \pm 0.05)$ \\
\hline 0.0 & 85 & 22 & 1.0 & 1.42 \\
\hline 0.05 & 86 & 22 & 1.0 & 1.44 \\
\hline 0.1 & 89 & 28 & 1.0 & 1.49 \\
\hline 0.5 & 99 & 25 & 1.0 & 1.66 \\
\hline 1.0 & 120 & 21 & 1.0 & 2.00 \\
\hline
\end{tabular}

The key model parameters for 60 / 40 SLES / SDS in $\mathrm{AlCl}_{3}$ at 5 and $10 \mathrm{mM}$ surfactant concentrations are summarised in table 3, and for the other SLES / SDS compositions studied (80 / 20, 50 / 50, and 20 / 80) in table S7 in the Supporting Information. Over most of the range of parameters explored the core-shell model is a good description of the scattering profile, and gives rise to an inner core radius $\sim 17 \AA$ and a total radius $\sim 20 \AA$. In the absence of electrolyte 
the micelle aggregation numbers are similar to those previously reported for SDS and SLES $(23,47,57)$.

For the micelles observed at a surfactant concentration of $10 \mathrm{mM}$ the micelle growth with the addition of $\mathrm{AlCl}_{3}$ is relatively modest. The inter-micelle interactions, which result in the reduction in scattered intensity at low Q, remains evident in the data. From this (see Experimental Details in the Supporting Information) the surface charge on the micelle and hence the degree of ionisation of the micelle is determined. It is comparable to that reported in related systems $(23,29,48)$. At the lower surfactant concentrations, 2 and $5 \mathrm{mM}$, the micelle growth with the addition of $\mathrm{AlCl}_{3}$ is more significant and the increasingly elongated micelle form factor now masks the sensitivity of the model to the surface charge. Hence in those cases it is undetermined and is set as zero in the associated model parameter tables.

The SANS measurement were made for two isotopic combinations of the surfactants, h-SLES / h-SDS and h-SLES / d-SDS in $\mathrm{D}_{2} \mathrm{O}$. Although, as described earlier, the two complementary sets of data provide a direct measure of the micelle composition, they also provide an additional constraint in the modelling of the micelle structure. In practice the two data sets are modelled / refined separately and acceptable model fits required that the model parameters for each contrast were within error. This is illustrated in table S6 in the Supporting Information for 10 $\mathrm{mM}$ 60/40 SLES / SDS in $\mathrm{AlCl}_{3}$, and show good correspondence between the equivalent data sets and the model parameters. In the other tables of model parameters the parameters quoted are an average of the parameters for the two contrasts measured.

As the increase in the micelle aggregation number with increasing $\mathrm{AlCl}_{3}$ concentration is relatively modest over much of the concentration and composition range explored, the corresponding ellipticity, ee, deviation from spherical symmetry, is small. It varies typically in the range $\sim 1.3$ to $\sim 2.5$. The model constraint that the inner core is constrained to a maximum dimension of the fully extended alkyl chain of the surfactant, ext=1.0, is consistent with most of the data. However there is a region for the SLES / SDS compositions $\geq 50$ mole \% SLES and at the lower surfactant concentration, $5 \mathrm{mM}$, where at intermediate $\mathrm{AlCl}_{3}$ concentrations the data are not consistent with that constraint. In those cases the data can only be adequately modelled if ext $<1.0$, typically in the range 0.6 to 0.7 , see table $3 \mathrm{a}$ and tables $\mathrm{S} 7 \mathrm{a}$ and $\mathrm{b}$ in the Supporting Information); and this results in the inner core radius being $\sim 12$ to $15 \AA$ rather than $\sim 17 \AA$. This then results in a significant increase in the micelle ellipticity over a limited range of parameters, and we return to this point later in the discussion. 


\section{(e) Discussion}

\section{(i) Surface Properties}

One of the most important observations in this study is that in the presence of increasing $\mathrm{AlCl}_{3}$ concentrations SDS undergoes a broadly similar evolution in the surface structure, from monolayer, $\mathrm{S}_{1}$, to multilayer, $\mathrm{S}_{\mathrm{n}}$, adsorption via intermediate structures, $\mathrm{S}_{2}$ etc, as observed in other anionic surfactants (20-28). It was originally assumed that for the electrolyte induced layering to occur, a degree of tolerance to the effect of multivalent counterions to induce precipitation in anionic surfactants was required. Hence it is significant that for SDS, one of the anionic surfactants most susceptible to precipitation, behaves similarly to the surfactants more tolerant to multivalent counterion induced precipitation, such as SLES and MES. More recently, Thomas and Penfold (19), in a recent comprehensive review of multilayer formation at the interface, demonstrated that the onset of surface layering frequently occurs outside the regime of bulk precipitation. It was also concluded that the mechanism of surface layering was associated with the attractive forces produced by the correlated adsorption of multivalent counterions between adjacent layers and the relative proximity of an associate bulk lamellar phase. The results presented here very much support and reinforce those observations and hypotheses.

The other notable feature is that although for SLES and SDS, and as observed more extensively for SLES and MES (23-25, 27-29), the surface structure evolves from $S_{1}$ to $S_{n}$ via $S_{2}, S_{3}$ etc with increasing $\mathrm{AlCl}_{3}$ concentration, the evolution in the surface structure is more complex for the SLES / SDS mixtures. For the SDS / SLES mixtures, between the $S_{1} / S_{2}$ structures and the formation of the $\mathrm{S}_{\mathrm{n}}$ multilayer structures there is a region in $\mathrm{AlCl}_{3}$ concentrations where the surface reverts to a monolayer, $S_{1}$. What is clear from the surface phase diagram, see figure 3 , is that this region of monolayer adsorption at intermediate $\mathrm{AlCl}_{3}$ concentrations is systematic. It occurs over a relative narrow range of $\mathrm{AlCl}_{3}$ concentrations, between $\mathrm{AlCl}_{3}$ concentrations $\sim 0.1$ to $0.5 \mathrm{mM}$, and is in a region where no precipitation is evident.

In the SLES adsorption, for SLES molecules with longer alkyl chain lengths, $\mathrm{C}_{14}$ or $\mathrm{C}_{16}$ rather than $\mathrm{C}_{12}$, the effect of higher concentrations of $\mathrm{AlCl}_{3}$ on these more hydrophobic surfactants is to give rise to a transition from multilayer, $S_{n}$, to monolayer, $S_{1}$, adsorption (25). In that case this was a direct result of the precipitation of the bulk phase, resulting in the surface being now in equilibrium with a dilute solution which can now only support monolayer adsorption. The 
closer proximity and impact of precipitation was also attributed to the limited range of surface structure observed in the $\mathrm{C}_{16}-\mathrm{C}_{18}$ MES eutectic mixtures (39). What is different in the case of SLES and MES compared to the SLES / SDS mixtures, is that once the transition from multilayer to monolayer occurred, only monolayer adsorption was then observed at even higher $\mathrm{AlCl}_{3}$ concentrations.

For $\mathrm{C}_{14}-\mathrm{MES}$ it was shown that the presence of $\mathrm{CaCl}_{2}$ shifted the $\mathrm{AlCl}_{3}$ dependence of the surface structural evolution to higher $\mathrm{AlCl}_{3}$ concentrations, but that the same evolution from $S_{1}$ to $S_{2}$ to $S_{3} / S_{4}$ to $S_{n}$ occurred (28). Modifying the AES headgroup, from methyl to ethyl ester, resulted in surface ordering for the $\mathrm{C}_{14}$-EES in the presence of $\mathrm{AlCl}_{3}$ only in the form of $\mathrm{S}_{2}$ structures. Whereas in $\mathrm{CaCl}_{2} / \mathrm{AlCl}_{3}$ mixtures the surface structure evolved from $\mathrm{S}_{1}$ to $\mathrm{S}_{2}$ to $\mathrm{S}_{3}$ and back to $\mathrm{S}_{2}$ with increasing $\mathrm{AlCl}_{3}$ concentration in the presence of a fixed amount of $\mathrm{CaCl}_{2}$ (29). Although both of these trends observed in the $\mathrm{CaCl}_{2} / \mathrm{AlCl}_{3}$ mixtures are qualitatively different to the observations for the SLES / SDS mixtures, they do emphasise the importance of the relative strengths of the different counterion binding on the surface structure. Furthermore they show how the headgroup structure or environment can affect the binding and hence the surface structure.

The transition observed here, from an $S_{2}$ or $S_{3}$ structure (depending upon the SLES / SDS composition) to monolayer and then to $\mathrm{S}_{\mathrm{n}}$ as the $\mathrm{AlCl}_{3}$ concentration increases, requires a different mechanism to those previously discussed. The rational for this sequence of structural evolution is that as the $\mathrm{AlCl}_{3}$ concentration increases the solution structure evolves such that there is a preferential adsorption of the $\mathrm{Al}^{3+}$ counterions in the bulk phase, which depletes the $\mathrm{Al}^{3+}$ counterions available for surface ordering to take place. If sufficient then the surface reverts to monolayer adsorption, and only transforms again to the more extended surface multilayer structures at even higher $\mathrm{AlCl}_{3}$ concentrations when there is now sufficient $\mathrm{Al}^{3+}$ available for the surface. At this point the surfactant concentration and concentration of $\mathrm{Al}^{3+}$ ions are such that the multilayer structure, $S_{n}$, is now sustainable at the surface. This could be further driven by changes in the relative binding of $\mathrm{Na}^{+}$and $\mathrm{Al}^{3+}$ between the surface and the bulk aggregated structures.

Although the measurements have been made at a fixed surfactant concentration of $2 \mathrm{mM}$, which in the absence of electrolyte is below the mixed cmc of SLES / SDS, see figure 1, figure $\mathrm{S} 2$ and table $\mathrm{S} 1$, in the presence of $\mathrm{AlCl}_{3}$ the cmc rapidly decreases $(24,25)$ and the measurements in $\mathrm{AlCl}_{3}$ are all well in excess of the $\mathrm{cmc}$. The mixed $\mathrm{cmc}$ in the presence of 
$\mathrm{AlCl}_{3}$ is typically $\leq 0.3 \mathrm{mM}$, see surface tension data in figures $\mathrm{S} 3$ and $\mathrm{S} 4$ in the Supporting Information.

An analysis of the surface composition in the presence of $\mathrm{AlCl}_{3}$, for monolayer, $\mathrm{S}_{1}$, bilayer, $\mathrm{S}_{2}$, and multilayer, $\mathrm{S}_{\mathrm{n}}$, adsorption shows that the surface composition evolves with increasing $\mathrm{AlCl}_{3}$ concentration. That is, the surface which in the absence of electrolyte is SLES rich compared to the bulk solution, becomes less rich in SLES and richer in SDS in the monolayer, bilayer and multilayer structures. This might be expected to provide a more optimal balance in the packing between the SDS and the bulkier SLES headgroups which would optimise the $\mathrm{Al}^{3+}$ binding, and so minimise the surface free energy. An analagous optimisation in the bulk packing and hence relative binding of $\mathrm{Al}^{3+}$ and $\mathrm{Na}^{+}$may then be responsible for the depletion of the $\mathrm{Al}^{3+}$ counterions required to drive the appearance of monolayer adsorption observed at relatively high $\mathrm{AlCl}_{3}$ concentrations before multilayer adsorption occurs.

\section{(ii) Solution self-assembly}

The SANS measurements were made at surfactant concentrations of 2, 5, and $10 \mathrm{mM}$. In the absence of electrolyte the $2 \mathrm{mM}$ data are below the cmc and at $5 \mathrm{mM}$ the cmc is very close, especially for the SDS rich solution compositions. This has the result that the statistical quality of the data at $5 \mathrm{mM}$ is such that the errors in the modelling are relatively large.

At $10 \mathrm{mM}$ the data and modelling show a more reliable and consistent trend with solution composition. The aggregation number is $\sim 80$ to 85 and is within error constant with solution composition. The results are broadly consistent with those previously reported for SDS (47, 57) and for SLES (38). In detail the aggregation number for the SLES / SDS mixtures are systematically closer to those reported for SLES (36) than for SDS $(47,57)$; and implies that the presence of the SLES even for the more SDS richer compositions is dominating the micelle packing. This is also in part reflecting the observation at these relatively low surfactant concentrations, that even for the SDS rich solution compositions, the micelles are still overall richer in SLES, see figure S5 in the Supporting Information.

As discussed earlier in the presentation of the SANS results, the data at 2 and $5 \mathrm{mM}$ surfactant concentrations, although still consistent with small globular micelles, have a slightly different form. The suppression of the data at low $Q$, due to the inter-micelle interactions, $S(Q)$, is not evident. This has the consequences that it is difficult to determine the surface charge on the micelle. However the form factor, $\mathrm{P}(\mathrm{Q})$, is more consistent with more elongated micelle structures. This, in particular, results in a greater dependence on the $\mathrm{AlCl}_{3}$ concentration and, 
although still relatively modest, a greater increase in the micelle size with increasing $\mathrm{AlCl}_{3}$ concentration, see tables 3 and S7. The greater tendency for growth at the lower surfactant concentration was also reported recently by Wang et al (40) and Chen et al (57). In those cases it was attributed to the greater ionic strength relative to the micelle concentration and the reduced influence of inter-micellar interactions.

At $10 \mathrm{mM}$, where the surface charge on the micelle is determined, the degree of ionisation of the micelles is $\sim 0.3$ over the composition range measured. It is comparable to that reported for SDS (45), and is consistent with the dressed micelle model (58) and the molecularthermodynamic approach of Srinivasan and Blankschtein (59). The degree of ionisation for pure SLES is lower and typically $\leq 0.15(38)$. In that case the lower values were attributed to the presence of the ethylene oxide group resulting in a stronger degree of counterion binding. As observed in the corresponding surface behaviour, see earlier discussion, as soon as the SDS is present this behaviour is significantly altered and the degree of ionisation is, even for the SLES rich compositions studied, closer to that of SDS. Hence in the SLES / SDS mixtures although the aggregation numbers are closer to that for SLES the micelle charge is closer to that for SDS. From the law of mass action of micellisation (60), specific treatments of counterion binding (61) and the dressed micelle model (58) it is expected that the micelles that form close to the cmc are highly charged and that as the surfactant concentration increases the degree of ionisation decreases to an approximately constant value. This has been reported in related studies on SDS $(47,57,62,63)$, and for other globular micellar systems (29). As discussed earlier it is not possible to determine a reliable value of the surface charge on the micelle at the surfactant concentrations of 2 and $5 \mathrm{mM}$, even where the concentration is $>\mathrm{cmc}$, and at $10 \mathrm{mM}$ the degree of ionisation has already reached values consistent with that obtained at much higher concentrations. That is, the mixing of SLES and SDS seems to promote a more rapid evolution of the surface charge to a constant value, and is associated with the binding strength of the counterion in the mixed SLES / SDS headgroup region.

Within the surfactant and $\mathrm{AlCl}_{3}$ concentration range measured the extent of the variation in the micelle growth for the SLES / SDS mixtures is broadly comparable to those previously reported for MES and SLES $(24,25,27)$, as illustrated in figure 7 a for SLES and MES and in figure $7 \mathrm{~b}$ for SLES / SDS. 


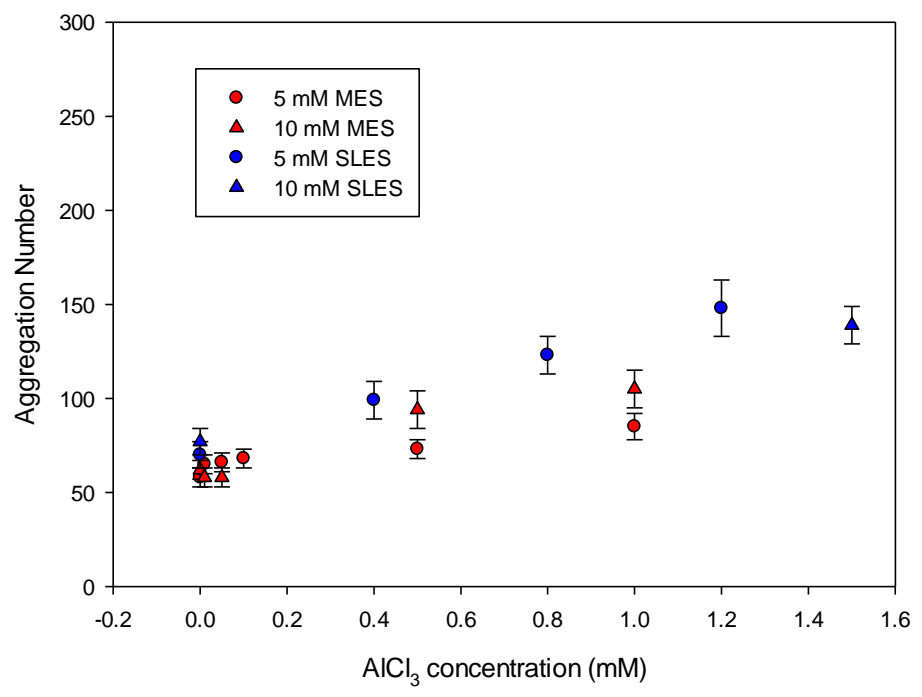

(a)

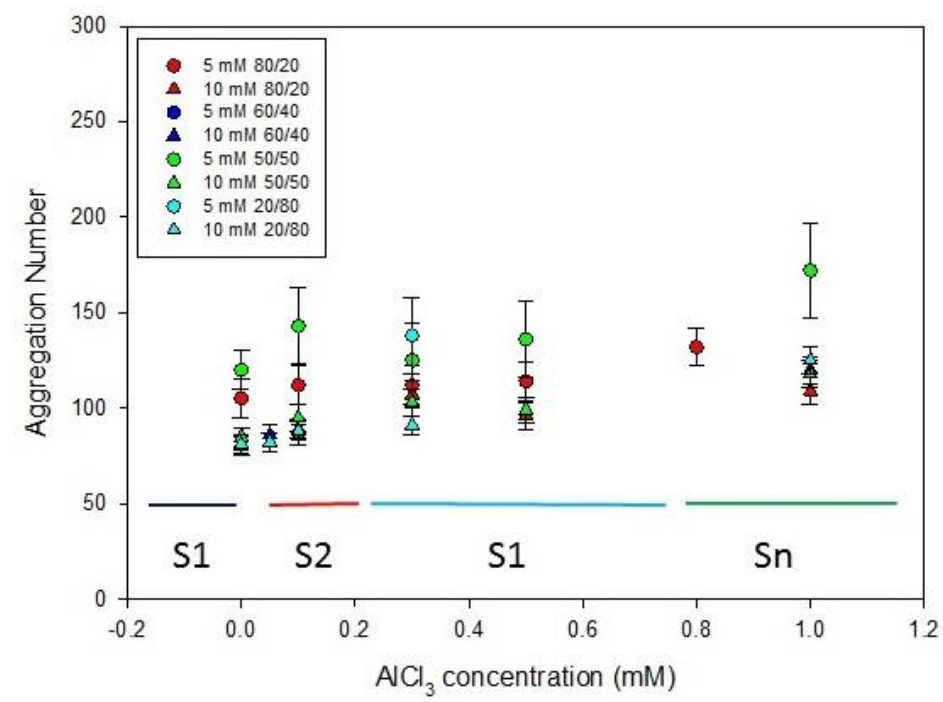

(b)

Figure 7. Variation in micelle aggregation number with $A{ }^{2} l_{3}$ concentration for (a) MES, SLES (data reproduced from references 22, 23, 25), (b) SLES / SDS: see legend for details. The bars at the bottom of figure $7 b$ show the approximate boundaries for the surface behaviour, taken from figure 3 and table 1. 
Although the magnitude of the variation is similar for MES and SLES and for the SLES / SDS mixture, the detailed variation has different forms. For MES and SLES at 5 and $10 \mathrm{mM}$ surfactant concentrations the variation in aggregation number shows an approximately linear increase, see figure 7a. For the SLES / SDS mixture, at 5 and $10 \mathrm{mM}$ and at different solution compositions, see figure $7 \mathrm{~b}$, the variation is quite different. For much of the data with increasing $\mathrm{AlCl}_{3}$ concentration there is an initial increase in the aggregation number, which is then followed by a region in which the variation is minimal and in some cases decreases, before it finally increases at even higher $\mathrm{AlCl}_{3}$ concentrations.

\section{(iii) Comparison of surface and self-assembly trends}

In figure $7 \mathrm{~b}$ the variation in micelle aggregation number at surfactant concentrations of 5 and $10 \mathrm{mM}$ and for the different SLES / SDS compositions measured is compared with the approximate surface phase behaviour, included from figure 3 and table 1 . The distinct regions in the surface phase behaviour, from monolayer $\left(S_{1}\right)$ to the initial surface layering $\left(S_{2}\right.$ or $\left.S_{3}\right)$ and finally to multilayers $\left(\mathrm{S}_{\mathrm{n}}\right)$, correlate with the trends in the aggregation number variation. That is, the initial surface layering coincides with the initial region of micellar growth due to $\mathrm{Al}^{3+}$ binding, the region where the surface reverts to a monolayer coincides with the region where the micellar growth is relatively constant or decreases, and finally the region of surface multilayer formation coincides with a region of stronger micellar growth at the higher $\mathrm{Al}^{3+}$ concentrations.

It is expected that the degree of ionisation of the micelle will gradually decrease as the amount of electrolyte added increases and the counterion binding increases $(47,58)$. Although not accessible for the SANS data at $5 \mathrm{mM}$, the model parameters for the data at $10 \mathrm{mM}$ for the SLES / SDS solution compositions of 80/20 and 50/50 mole ratio do show a distinct trend that again correlates with the surface behaviour. As such it broadly supports the changing degree of $\mathrm{Al}^{3+}$ binding in the micelle phase across the range of $\mathrm{Al}^{3+}$ concentrations explored, see figure 8. It is assumed that this impacts upon the amount of free $\mathrm{Al}^{3+}$ available to the surface structure. 


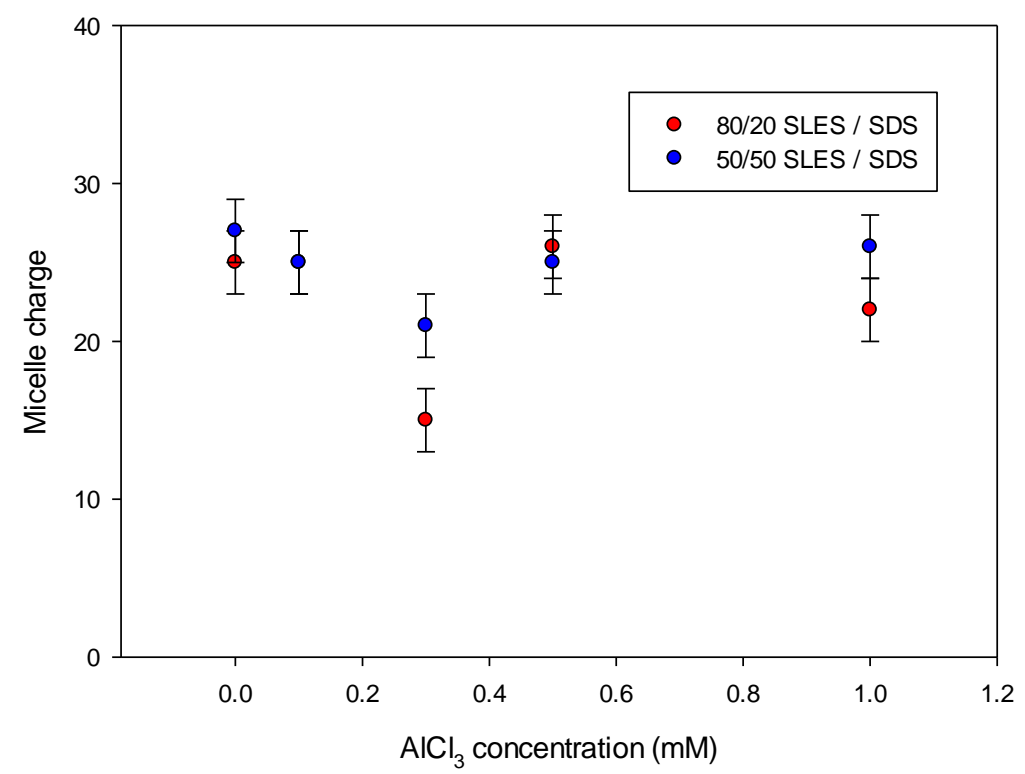

Figure 8. Variation in micelle surface charge for $10 \mathrm{mM}$ SLES / SDS (see legend for details).

Hence the variation in surface behaviour and the evolution of the micelle structure are closely related. As discussed earlier, in the context of the surface layering, it is postulated that this is directly related to the relative binding strengths of $\mathrm{Na}^{+}$and $\mathrm{Al}^{3+}$. The binding of $\mathrm{Al}^{3+}$ ions is what promotes the driving force for the surface layering and promotes the greater micelle growth. The relative binding strengths at $\mathrm{Na}^{+}$and $\mathrm{Al}^{3+}$ are important factors, as indicated by Alargova et al (6), and demonstrated by Xu et al (28), Wang et al (30), Lui et al (33), Xu et al (64) and Vlachy et al (52). Maneedaeng et al (11) have quantified the competitive counterion binding of $\mathrm{Na}^{+}$and $\mathrm{Ca}^{2+}$ to anionic micelles in studying mixed anionic micelles of SDS / sodium decyl sulfate, SDeS, and SDS / LAS. They demonstrated that although the relative amounts of $\mathrm{Na}^{+}$and $\mathrm{Ca}^{2+}$ binding vary the total degree of counterion binding remains approximately constant, and could be modelled using an equilibrium model relating the concentration of bound and unbound counterions. The complexity arising from the relative counterion binding strengths was also highlighted in the work of Dutkiewicz et al (66), who showed that the degree of counterion binding depended on the electrolyte concentration and the type of counterion. In their molecular dynamics simulation Sammalkorpi et al (67) showed how $\mathrm{CaCl}_{2}$ compared to $\mathrm{NaCl}$ resulted not only in larger micelles but a more compact densely packed structure. This will affect the relative ion binding in the presence of mixed counterions and the opportunity for ion-bridging. 
There is a strong correlation between the unusual evolution in the surface layering in the SLES / SDS mixtures with increasing $\mathrm{AlCl}_{3}$ concentration and the evolution of the mixed mixcelle formation. Hence, as discussed earlier, it is postulated that the unusual variations in the surface layering are as a result of changes in the relative binding of $\mathrm{Al}^{3+}$ and $\mathrm{Na}^{+}$counterions in the mixed micelles due to differences in the packing constraints imposed by the mixed SLES and SDS headgroups, and hence the amount of $\mathrm{Al}^{3+}$ bound to the micellar phase. This in turn results in changes in the $\mathrm{Al}^{3+}$ binding to the surface and the amount of free $\mathrm{Al}^{3+}$ available for surface binding; and promotes the region of monolayer adsorption between the two regions of surface layering and surface multilayer formation.

\section{CONCLUSIONS}

In the presence of $\mathrm{AlCl}_{3}$ a sequence of increasingly extended surface multilayer structures, from $S_{1}$ to $S_{n}$, via $S_{2}, S_{3}$ etc, is observed for SDS. The structures observed are broadly similar to those previously reported for SLES (23-25), and MES (27-29, 39). The results importantly demonstrate that a tolerance to precipitation in the presence of multivalent counterions is not a necessary requirement for the occurrence of surface ordering. The results reinforce the more recent discussions about the origins at the attractive force associated with the surface ordering and the proximity of a bulk lamellar phase (19).

In the SLES / SDS mixtures at intermediate $\mathrm{AlCl}_{3}$ concentrations a different sequence of surface layering occurs. There is a narrow range of $\mathrm{AlCl}_{3}$ concentrations in the which the surface structure changes to a monolayer. This occurs between the transition from an $S_{2}$ or $S_{3}$ structure to the multilayer, $\mathrm{S}_{\mathrm{n}}$, structure, and is different to what has been previously reported $(25,39)$. The appearance of the monolayer surface phase between $S_{2} / S_{3}$ and $S_{n}$ is rationalised as resulting from a partial depletion of $\mathrm{Al}^{3+}$ due to changes in the bulk aggregated phase and changes in the relative binding of $\mathrm{Na}^{+}$and $\mathrm{Al}^{3+}$ counterions on the micelles and at the surface. The SANS data for the SLES / SDS mixtures are consistent with relatively small globular micelles, and show a modest increase with increasing $\mathrm{Al}^{3+}$ concentration. The trends with increasing $\mathrm{Al}^{3+}$ concentration are in detail different to those previously reported for SLES and MES $(24,25,27)$. They illustrate a more complex evolution in the pattern of growth which correlates strongly with the variation in the surface behaviour. These observations further support the hypothesis relating to the relative binding of $\mathrm{Na}^{+}$and $\mathrm{Al}^{3+}$ counterions in the bulk phase, resulting in changes to the availability and binding of $\mathrm{Al}^{3+}$ ions in the surface phase. 
The results for SDS and the SLES / SDS mixtures reinforce the richness and complexity of the surface layering in the presence of multivalent counterions $(18,19)$, and further indicate the importance of the relative counterion binding, and the evolution of the bulk aggregated phase. Furthermore it further illustrates the opportunity for manipulating these surface multilayer structures by using mixtures of surfactants with different molecular structures as already to some extent demonstrated in the studies of mixtures of LAS isomers (22), MES mixtures (39), and anionic / nonionic surfactant mixtures $(20,21,23)$. Future measurements to explore how a wider range of surfactant structures and the mixing of different structures can be used to control surface multilayer formation and direct measurements of the relative counterion binding will greatly enhance our understandingof the underlying mecahnisms.

\section{ACKNOWLEDGEMENTS}

We acknowledge the provision of neutron beam time at the ISIS neutron facility, and the invaluable scientific and technical support on the CRISP and SURF reflectometers and the LARMOUR instrument. We have also benefited from the provision and characterisation of deuterium labelled surfactants from the ISIS Deuteration Laboratory. The authors also thank the China Scholarship Council, CSC, for their financial support. 


\section{REFERENCES}

(1) J J Scheibel, The evolution of anionic surfactant technology to meet the requirements of the laundry detergent industry, J. Surf. Deter. 2004, 7, 319-329

(2) Y U Yangxin, Z Jin, A E Bayley, Development of surfactants and builders in detergent formulations, Chin. J. Chem. Eng. 2008, 16, 517-527

(3) P J Missel, N A Mazer, M C Carey, G B Benedek, Sphere to rod transition in the shape of anionic micelles determined by surface tension measurements, J. Phys. Chem. 1989, 93, 8354-8360

(4) N M Van Os, J R Haak, L A M Rupert, Physico-chemical properties of selected anionic, cationic and nonionic surfactants, Elsevier, Amsterdam, 1993

(5) R G Alargova, J T Petkov, D N Petsev, I B Ivanov, G Broze, A Mehreteab, Light scattering study of sodium dodecyl polyoxyethylene - 2- sulfonate micelles in the presence of multivalent counterions, Langmuir, 1995, 11, 1530-1536

(6) R G Alargova, V P Ivanova, P A Kralchevsky, A Mahreteab, G Broze, Growth of rodlike micelles in anionic surfactant solutions in the presence of $\mathrm{Ca}^{2+}$ counterions, Coll. Surf. A, 1998, 142, 201-218

(7) J R Lu, R K Thomas, J Penfold, Surfactant layers at the air-water interface: structure and composition, Adv. Coll. Int. Sci. 2000, 84, 143-304

(8) B L Chou, J H Bae, Surfactant precipitation and redissolution in brine, J. Coll. Int. Sci. 1983, 96, 192-203

(9) P Somasundaran, K P Ananthapadmanbhan, M S Celik, Precipitation - redissolution phenomena in sulfonate- $\mathrm{AlCl}_{3}$ solutions, Langmuir, 1988, 4, 1061-1062

(10) P Paton-Morales, F I Talens-Alesson, Effect of competitive adsorption of $\mathrm{Zn}^{2+}$ on the flocculation of Lauryl sulfate micelles by $\mathrm{Al}^{3+}$, Langmuir, 2002, 18, 8295-8301

A Maneedaeng, K J Haller, B P Grady, A E Flood, Thermodynamic parameters and counterion binding in binary anionic surfactants, J. Coll. Int. Sci. $2011,356,598-604$

(12) P Paton-Morales, F I Talens-Alesson, Effect of ionic strength and competitive adsorption of $\mathrm{Na}^{+}$on the flocculation of Lauryl sulfate micelles with $\mathrm{Al}^{3+}$, Langmuir, 2001, 17, 6059-6064 

precipitation of surfactants. I. Anionic surfactants with calcium and with cationic surfactants, J. Surf. Det. 2001, 4, 10-14

C H Rodriquez, J F Scamehorn, Kinetics of precipitation of surfactants, II. Anionic surfactant mixtures, J. Surf. Det. 2001, 4, 15-26

J F Scamehorn, S D Christian, R T Ellington, in Surfactant based separation processes, J F Scamehorn, J H Harwell (Eds), Surfactant Science Series, Vol 33, Marcel Dekker, New York, 1989.

K Hac-Wylo, I Palasinska, P Miskowiec, The comparative studies of the ability of anionic surfactants to bind Lead (II) ions, J. Mol. Liq. 2016, 219, 1071-1077

K L Steller, J F Scamehorn, Surfactant precipitation in aqueous solutions containing mixtures of anionic and nonionic surfactants, J. Am. Oil Chem. Soc. 1986, $63,566-574$

(18) R K Thomas, J Penfold, Multilayering of surfactant systems at the air-water dilute aqueous solution interface, Langmuir, 2014, 31, 7440-5450

P X Li, J Penfold, R K Thomas, H Xu, Multilayers formed by polyelectrolytesurfactant and related mixtures at the air-water interface, Adv. Coll. Int. Sci. 2019, 269, 43-86

J Penfold, R K Thomas, C C Dong, I Tucker, K Metcalfe, S Golding, I Grillo, Equilibrium surface adsorption behaviour in complex anionic / nonionic surfactant mixtures, Langmuir, 2007, 23, 10140-10149

(21) J Penfold, R K Thomas, C C Dong, I Tucker, K Metcalfe, S Golding, C Gibson, I Grillo, Surface and solution properties of anionic / nonionic surfactant mixtures of alkyl benzene sulfate and triethylene glycol decyl ether, Langmuir, 2010, 26, 10614-10626

J Penfold, R K Thomas, C C Dong, I Tucker, K Metcalfe, S Golding, C Gibson, I Grillo, The adsorption and self-assembly of mixtures of alkylbenzene sulfate isomers and the role of divalent ions, Langmuir, 2011, 27, 6674-6684 J T Petkov, I M Tucker, J Penfold, R K Thomas, D N Petsev, C C Dong, S

Golding, I Grillo, The impact of multivalent counterions $\mathrm{Al}^{3+}$ on the surface adsorption and self-assembly of the anionic surfactant alkyloxyethylene sulfate and anionic / nonionic surfactant mixtures, Langmuir, 2010, 26, 16691-16709

H Xu, J Penfold, R K Thomas, J T Petkov, I Tucker, J R P Webster, The formation of surface multilayers at the air-water interface from sodium polyetheylne 
glycol monoalkyl ether sulfates / $\mathrm{AlCl}_{3}$ solutions: the role of the size of the polyethylene oxide group, Langmuir, 2013, 29, 11656-11666

H Xu, J Penfold, R K Thomas, J T Petkov, I Tucker, J R P Webster, The formation of surface multilayers at the ait-water interface from sodium polyethylene glycol monoalkyl ether sulfates / $\mathrm{AlCl}_{3}$ solutions: the role of the alkyl chain length, Langmuir, 2013, 29, 11744-11753 R K Thomas, J Penfold, H Xu, P X Li, K Ma, D W Roberts, J T Petkov, R Welbourn, Adsorption of methyl ester sulfonates at the air-water interface: can limitations in the application of the Gibbs equation be overcome by 'computer purification', Langmuir, 2017, 33, 9944-9953

H Xu, R K Thomas, J Penfold, P X Li, K Ma, R J L Welbourn, D W Roberts, J T Petkov, The impact of electrolyte on the adsorption of the anionic surfactant methyl ester sulfonate at the air-water interface: surface multilayer formation, J. Coll. Int. Sci, 2018, 512, 231-238

H Xu, P X Li, K Ma, R K L Welbourn, J Penfold, R K Thomas, D W Roberts, $\mathrm{J}$ T Petkov, The role of competitive counterion adsorption on the electrolyte induced surface ordering in methyl ester sulfonate surfactants at the air-water interface, J Coll. Int. Sci. 2019, 533, 154-160

$$
\text { Z Wang, P X Li, K Ma, Y Chen, M Campana, J Penfold, R K Thomas, D W }
$$

Roberts, H Xu, J T Petkov, Z Yan, Impact of molecular structure, headgroup and alkyl chain geometry on the adsorption of the anionic ester sulfonate surfactants at the airwater interface in the presence and absence of electrolyte, J. Coll. Int. Sci. 2019, 544, 293-302

R G Alargova, J T Petkov, D N Petsev, Micellisation and interfacial properties of alkyloxyethylene sulfate surfactants in the presence of multivalent counterions, J. Coll. Int. Sci. 2003, 261, 1-11

L M Bergstrom, A Tehrani-Bagha, G Nagly, Growth behaviour, geometrical shape and second cmc of micelles formed by cationic gemini esterquat surfactants, Langmuir, 31, 2015, 4644-4653

G V Jensen, R Lund, J Gummal, T Narayanan, J S Pedersen, Monitoring the transition from spherical to polymer-like surfactant micelles using SAXS, Agnew Chem. Int. Ed. 53, 2014, 11524-11528

$$
\text { Z Lui, M Cao, Y Chen, Y Fan, D Wang, H Xu, Y Wang, Interactions of }
$$

divalent and trivalent metal counterions with anionic sulfonate gemini surfactants and 
induced aggregation transitions in aqueous solution, J. Phys. Chem. B, 120, 2016, $4102-4113$

(34) J H Mu, G Z Zi, Rheology of viscoelastic anionic micelle solutions in the presence of multivalent counterions, Coll. Polym. Sci. 279, 2001, 872-875

K D Danov, P A Kralchevsky, S D Stoyanov, J L Cook, I P Scott, Analytical modelling of micellar growth. 1. Chain conformation free energy of binary spherical, wormlike and lamellar micelles, J. Coll. Int. Sci. 547, 2019, 245-255

R C Alargova, K D Danov, J T Petkov, P A Kralchevsky, G Broze, A

Mahreteab, A sphere-rod transition in the shape of anionic micelles determined by surface tension measurements, Langmuir, 13 1997, 5544-5551

R C Alargova, K D Danov, J T Petkov, P A Kralchevsky, G Broze, A

Mahreteab, Growth of giant rod-like micelles of ionic surfactants in the presence of $\mathrm{Al}^{3+}$ counterions, Langmuir, 14, 1998, 4036-4049

H Xu, J Penfold, R K Thomas, J T Petkov, I Tucker, A Terry, The impact of $\mathrm{AlCl}_{3}$ on the self-assembly of the anionic surfactant sodium oligoethylene glycol monoalkyl ether sulfate in aqueous solution, Langmuir, 2013, 29, 13359-13366 H Xu, P Li, K Ma, R J L Welbourn, J Doutch, J Penfold, R K Thomas, D W Roberts, J T Petkov, K L Choo, S Y Khoo, Adsorption and self-assembly in methyl ester sulfonate surfactants, their eutectic mixtures and the role of electrolyte, J. Coll. Int. Sci. 2018, 516, 456-465

(40) Z Wang, P Li, K Ma, Y Chen, J Penfold, R K Thomas, D W Roberts, H Xu, J T Petkov, A Yan, D A Venero, The structure of alkyl ester sulfonate surfactant micelles: the impact of different valence electrolytes and surfactant structure on micelle growth, J. Coll. Int. Sci. 557, 2019, 124-134

CRISP reflectometer at the ISIS neutron source,

\section{https://www.isis.stfc.ac.uk/CRISP}

SURF reflectometer at the ISIS neutron source,

\section{http://www.isis.stfc.ac.uk/SURF}

(43) J Penfold, R K Thomas, the application of specular neutron reflection of neutrons to the study of surfaces and interfaces, J Phys: Condens Matter, 1990, 2, $1369-1412$

P X Li, K Ma, RK Thomas, J Penfold, Analysis of the asymmetrical synergy in the adsorption of zwitterionic - ionic surfactant mixtures at the air-water interface below and above the cmc, J. Phys. Chem. B 2016, 120, 3677-3691 
Webster, Surfactant adsorption in ternary surfactant mixtures above the cmc: the importance of the shape of the excess free energy, J. Phys. Chem. B, 2017, 121, 28252838

M Mulder, XSX Li, M M Nazim, R M Dalgleish, B Tan, M Buijse, J van

Wunnik, W G Bouwman, Systematically quantifying oil-water microemulsion structures using (spin echo) SANS, Coll. Surf. A, 2019, 575, 166-175

J B Hayter, J Penfold, Determination of micelle structure and charge by small angle neutron scattering, Coll. Polym. Sci. 1983, 261, 1022-1030

(48) J B Hayter, J Penfold, An analytic structure factor for macroion solutions, Mol. Phys. 1981, 42, 109-118

J Penfold, E Staples, L Thompson, I Tucker, J Hines, R K Thomas, J R Lu,

Solution and adsorption behaviour of mixed surfactant systems, SDS / $\mathrm{C}_{12} \mathrm{E}_{6}$,

Langmuir, 1995, 11, 2496-2508

(50) J Liley, R K Thomas, J Penfold, I M Tucker, J T Petkov, P Stevenson, J R P

Webster, The impact of electrolyte on the adsorption at the air-water interface in ternary surfactant mixtures above the cmc, Langmuir, 2017, 33, 4301-4312

(51) P M Holland, Non-ideal multicomponent mixed micelle model, Adv. Coll. Int. Sci. 1986, 26, 111-129

(52) P M Holland, D N Rubnigh, Non-ideal multicomponent mixed micelle model, J. Phys. Chem. 1983, 87, 1984-1990

(53) Phenomena in mixed surfactant systems, Ed J F Scamehorn, ACS Symposium Series No 311, Washington DC, 1986

(54) I M Tidswell, B M Ocko, P S Pershan, S R Wassermann, G M Whitesides, J D Axe, X-ray specular reflection studies on silicon coated by organic multilayers (alkyl siloxanes), Phys. Rev. B, 1990, 41, 1111-1128

S K Sinha, M K Sanyal, S K Satija, C F Majkrzak, D A Neumann, H Homma, S Szpala, H Gibaud, H Morkov, X-ray scattering studies from surface roughness of GaAs / AlAs multilayers, Physica B, 1994, 198, 72-77

(56) S Vora, A George, H Desai, P Bahadur, Mixed micelles of some anionicanionic, cationic-cationic and ionic-nonionic surfactats in aqueous media, J. Surf. Det. 1999, 2, 213-221 

aggregation behaviour of Gemini-like surfactants formed from SDS and diamines with hydrophobic and hydrophilic spacers, Soft Matter, 2017, 13, 8980-8989

(58) J B Hayter, A self-consistent model of dressed micelles, Langmuir, 1992, 8, 2873-2876

(59) V Srinivasan, D Blankschtein, Effect of counterion binding on micellar solution behaviour. 1. Molecular-thermodynamic theory of micellisation of ionic surfactants, Langmuir, 2003, 19, 9932-9945

(60) A I Rusanov, The mass action law theory of micellar solutions, Adv. Coll. Int. Sci. 1993, 45, 1-78

(61) E Ruckenstein, J A Beuren, Effect of counterion binding on micellisation, Langmuir, 1988, 4, 77-90

(62) N V Lebedeva, A Shahine, B L Bales, Aggregation number based degree of counterion dissociation in sodium n-alkyl sulfate micelles, J. Phys. Chem. B, 2005, $109,19806-19816$

P C Griffiths, A Paul, R K Heenan, J Penfold, R Ranganathan, B L Bales, Role of counterion concentration in determining micelle aggregation: evaluation of the combination of constraints from small angle neutron scattering, electron paramagnetic resonance and time resolved fluorescence quenching, J Phys. Chem. B, 2004, 108, 3810-3816

(64) H Xu, J Penfold, R K Thomas, J T Petkov, I Tucker, J R P Webster, I Grillo, A Terry, Ion specific effects in trivalent counterion induced surface and solution selfassembly of the anionic surfactant sodium polyethylene glycol monododecyl ether sulfate, Langmuir, 2014, 30, 4694-4702

(65) N Vlachy, M Drechsler, J M Verbavatz, D Touraud, W Kunz, Role of the surfactant headgroup in counterion specificity in the micelle to vesicle transition through salt addition, J. Coll. Int. Sci. 319, 2008, 542-548

(66) E Dutkiewicz, A Jakabuowska, Effects of electrolytes on the physicochemical behaviour of SDS micelles, Coll. Polym. Sci. 2002, 280, 1009-1014

(67) M Sammalkorpi, M Karttunen, M Haataja, Ionic surfactant aggregates in saline solutions, SDS in the presence of excess $\mathrm{NaCl}$ and $\mathrm{CaCl}_{2}$, J. Phys. Chem. B, $2009,113,5863-5870$ 


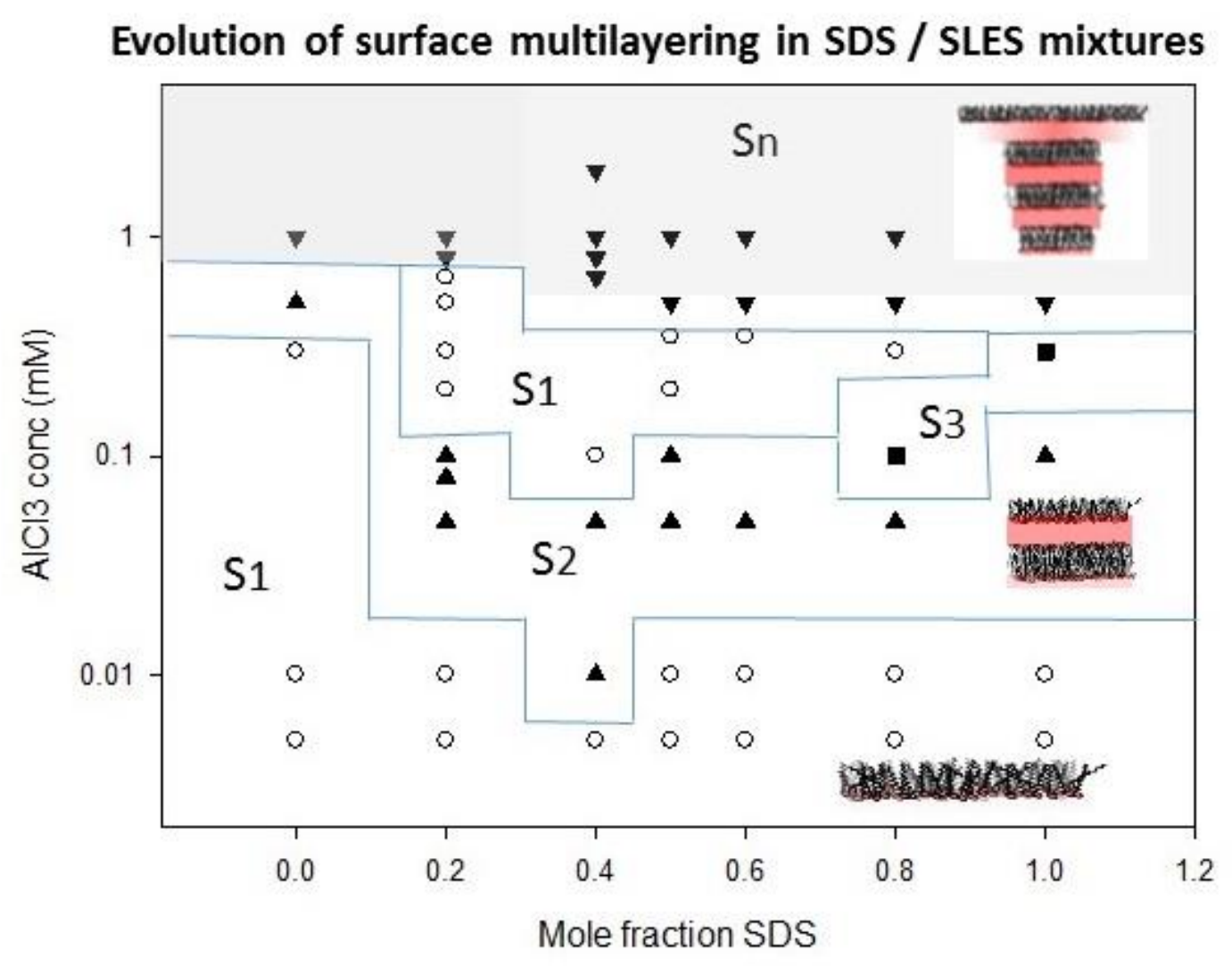

